\title{
Regulation of Dynamic Protein S-Acylation
}

\author{
Jessica J. Chen ${ }^{* t}$, Ying Fan ${ }^{\dagger}$ and Darren Boehning \\ Department of Biomedical Sciences, Cooper Medical School of Rowan University, Camden, NJ, United States
}

Protein S-acylation is the reversible addition of fatty acids to the cysteine residues of target proteins. It regulates multiple aspects of protein function, including the localization to membranes, intracellular trafficking, protein interactions, protein stability, and protein conformation. This process is regulated by palmitoyl acyltransferases that have the conserved amino acid sequence DHHC at their active site. Although they have conserved catalytic cores, DHHC enzymes vary in their protein substrate selection, lipid substrate preference, and regulatory mechanisms. Alterations in $\mathrm{DHHC}$ enzyme function are associated with many human diseases, including cancers and neurological conditions. The removal of fatty acids from acylated cysteine residues is catalyzed by acyl

\section{OPEN ACCESS}

Edited by:

Andrei Surguchov,

University of Kansas Medical Center,

United States

Reviewed by:

William Fuller,

University of Glasgow,

United Kingdom

Javier Valdez Taubas,

National University of Cordoba

(CIQUIBIC), Argentina

*Correspondence:

Jessica J. Chen

chenj@rowan.edu

${ }^{\dagger}$ These authors have contributed equally to this work

Specialty section: This article was submitted to

Cellular Biochemistry,

a section of the journal

Frontiers in Molecular Biosciences

Received: 20 January 2021

Accepted: 16 February 2021

Published: 26 April 2021

Citation:

Chen JJ, Fan Y and Boehning D (2021)

Regulation of Dynamic Protein

S-Acylation.

Front. Mol. Biosci. 8:656440.

doi: $10.3389 /$ fmolb.2021.656440 protein thioesterases. Notably, S-acylation is now known to be a highly dynamic process, and plays crucial roles in signaling transduction in various cell types. In this review, we will explore the recent findings on protein S-acylation, the enzymatic regulation of this process, and discuss examples of dynamic S-acylation.

Keywords: S-acylation, DHHC enzymes, APT, ABHD, cell signaling

\section{INTRODUCTION}

Protein lipidation is the co-translational or post-translational covalent addition of a variety of lipids to target proteins. Lipidation of proteins plays an important role in the regulation of cellular functions by affecting protein activity, localization, and stability (Wang and Casey, 2016; Zurzolo and Simons, 2016; Jiang et al., 2018). At least five different lipid classes are enzymatically attached to proteins, including glycosylphosphatidylinositol (GPI) anchors, isoprenoids, sterols, phospholipids and fatty acids. The GPI anchor attaches proteins to the exterior surface of the cell through a glycolipid containing phosphatidylinositol. The attachment of a GPI anchor occurs at the carboxyterminus and is mediated by more than 20 enzymes (Resh, 2013; Masuishi et al., 2016). Protein $O$-cholesterylation is the attachment of a sterol group to the C-terminus of a protein. This modification is especially common in the mammalian Hedgehog protein family, which are secreted proteins that have signaling function in regulating many tissues and structures in development (Nüsslein-Volhard and Wieschaus, 1980; Porter et al., 1996). N-Myristoylation is an irreversible covalent attachment of a 14-carbon saturated fatty acid to Gly residues on the N-terminus of proteins (Carr et al., 1982). Myristoylation occurs after the methionine aminopeptidase processing of the initiator methionine exposes the Gly residue at position 2 (Wilcox et al., 1987). Many proteins involved in signaling pathways, apoptosis, cancer, and viral replication are known to be myristoylated (Thinon et al., 2014). Protein prenylation adds the 15carbon farnesyl motif or the 20-carbon geranylgeranyl motif to target proteins (Kamiya et al., 1978). In general, prenylation is an enzymatically mediated multi-step process that adds hydrophobic prenyl moieties to the C-terminal cysteines of substrate proteins. Three different protein prenyltransferases-farnesyltransferase and geranylgeranyltransferases I and II-catalyze protein 
prenylation. Prenylation is a clinically important regulator of Ras protein function (Jackson et al., 1990).

There are many detailed reviews outlining the consensus sequences, enzymatic regulators, and functional outcomes of different classes of lipid post-translational modification (Resh, 2013; Chen and Boehning, 2017; Chen et al., 2018; Jiang et al., 2018). For this review, we will be focusing on protein acylation. Fatty acyl groups such as palmitate can be added to glycine or lysine (N-acylation), serine or threonine (O-acylation), and cysteines (S-acylation) (Kleuss and Krause, 2003; Buglino and Resh, 2008; Zou et al., 2011; Jing et al., 2017). For the rest of this review, we specifically discuss S-acylation, the covalent linkage of various fatty acids (14-20 carbons) via a thioester bond to the cysteine residues of substrate proteins. While the majority of the lipid modifications to proteins are irreversible, S-acylation is reversible and can be highly dynamic. When looking at S-acylation turnover on a proteomic scale, the majority of proteins have minimal turnover during the course of several hours, suggesting they are stably modified (Martin et al., 2012). However, a subset of proteins are dynamically S-acylated and they are implicated in key cellular events such as cell growth. One of the most well-known lipids involved in S-acylation is the 16carbon saturated palmitic acid. However, studies have shown that various saturated and unsaturated fatty acids, including oleic acid (Liang et al., 2001; Montigny et al., 2014; Thinon et al., 2016), steric acid (Kordyukova et al., 2008; Senyilmaz et al., 2015; Thinon et al., 2016), and arachidonic acid (Liang et al., 2001), can be incorporated onto cysteine residues in substrate proteins. In human platelets, $74 \%$ of the fatty acids linked to proteins via thioester bonds are palmitic acid, followed by about $22 \%$ stearic acid and 4\% oleic acid (Muszbek et al., 1999). Studies using bovine retina, heart, and liver proteins also showed a variety of thioester-linked fatty acids, with palmitic and stearic acids being the top two most abundant lipid modifications (DeMar Jr and Anderson, 1997).

Perhaps not surprisingly, the profile of fatty acids conjugated to S-acylated proteins depends on the exogenous supply of fatty acids (Muszbek et al., 1999; Webb et al., 2000), For example, incubation of human platelets with exogenous palmitate and stearate increased the amount of proteins palmitoylated and stearylated by $26 \%$ and $30 \%$, respectively (Muszbek et al., 1999). However, how S-acylation lipid profiles are regulated endogenously remains unclear. Additionally, the lipid species added can vary from cysteine to cysteine on the same protein (Brett et al., 2014). For example, the Influenza A virus protein hemagglutinin has three S-acylated cysteines, one of which is exclusively modified with the 18-carbon stearic acid (Kordyukova et al., 2008). While majority of the studies focus on palmitoylation, it is worth noting that incorporation of other fatty acids can lead to different functional outcomes (Liang et al., 2001; Senyilmaz et al., 2015). The prevalence or functional significance of fatty acids other than palmitic acid on majority of the S-acylated proteins is not fully understood.

To date, there is no universal consensus sequence for S-acylation sites (Salaun et al., 2010). However, there are some recurring patterns in specific classes of proteins. Src family kinases (Shenoy-Scaria et al., 1993; Koegl et al., 1994) and some of the heterotrimeric G proteins (Clapham and Neer, 1993; Linder et al., 1993) are acylated at N-terminal cysteines adjacent to the myristoylation site. Ras proteins have acylated cysteines adjacent to the C-terminal prenylation sites (Hancock et al., 1989). Many transmembrane proteins, such as claudin proteins found at tight-junctions (Rodenburg et al., 2017), are acylated at juxtamembrane positions. It is worth noting that we are just starting to appreciate the prevalence of S-acylation-approximately $20 \%$ of the mammalian proteome is predicted to be acylated (Blanc et al., 2019). One of the most widely used S-acylation databases is SwissPalm (Blanc et al., 2015). The recently updated SwissPalm 2 includes data from 38 palmitoylproteomic studies across 17 species (Blanc et al., 2019).

Recently, there is growing interest in understanding the enzymes regulating the highly dynamic S-acylation cycle on signaling proteins. As noted above, palmitoyl acyltransferases (PATs) catalyze the addition of fatty acyl groups (Lobo et al., 2002; Roth et al., 2002; Mitchell et al., 2006) while acyl proteins thioesterases (APTs) (Duncan and Gilman, 1998; Tomatis et al., 2010 ) and the $\alpha / \beta$ hydrolase domain (ABHD) proteins (Lin and Conibear, 2015) are responsible for the removal of Acyl groups. In this review, we will discuss recent developments in understanding both classes of enzymes. We will also summarize the functions of protein S-acylation by providing examples from the literature. Additionally, we will describe the methods used to study S-acylation and discuss their pros and cons. Finally, we will provide three examples of dynamic acylation in different cell types and the enzymatic machineries that tightly regulate them.

\section{FUNCTIONAL OUTCOMES OF S-ACYLATION}

\section{Membrane Localization}

Many membrane-associated proteins without a transmembrane domain require the conjugation of fatty acids for targeting to the membrane surface. Interestingly, different types of lipid modifications often exist on the same protein to achieve stable membrane attachment. For example, multiple members of the heterotrimeric G protein family (Clapham and Neer, 1993; Linder et al., 1993) and the Src family kinases (Shenoy-Scaria et al., 1993; Koegl et al., 1994) have other forms of lipidation in addition to S-acylation. Prenylation and myristoylation of proteins lead to transient and weak binding to lipid bilayers, and therefore are often not sufficient for reliable membrane targeting (Bhatnagar and Gordon, 1997). Fatty acids attached via S-acylation groups often leads to a more thermodynamically and kinetically stable binding to the membrane (Shahinian and Silvius, 1995). Since all known PATs are integral membrane proteins, it is proposed that other lipid modifications and/or intrinsic membrane affinity of peripheral protein substrates bring them in proximity to the PATs to facilitate S-acylation (Chamberlain and Shipston, 2015). For example, mutations of the prenylation sites in Ras proteins lead to decreased acylation (Hancock et al., 1989).

Lipid bilayers contain microdomains that are enriched in cholesterol and sphingolipids, commonly known as lipid rafts 
or liquid-ordered domains [reviewed in Levental et al. (2020)]. These microdomains have structural and functional importance in signaling transduction, endocytosis, and other cellular events (Simons and Toomre, 2000; Parton and Richards, 2003). We will refer to these lipid microdomains for the remainder of this review as lipid rafts. S-acylated proteins are known to be enriched in lipid rafts because long saturated acyl chains favor partitioning into the highly ordered environment created by cholesterol and sphingolipids [reviewed in Levental et al. (2010)]. One example is the influenza viral membrane protein hemagglutinin. S-acylation is important for its association with lipid rafts (Melkonian et al., 1999), which subsequently facilitates viral replication (Zurcher et al., 1994) and viral fusion (Naeve and Williams, 1990). Non-acylated hemagglutinin fails to cluster in lipid rafts, which later become the fusion sites (Takeda et al., 2003). Similarly, multiple members of the $\mathrm{T}$ cell receptor complex (Rodgers et al., 1994; Arni et al., 1996; Parolini et al., 1996; Harder and Kuhn, 2000) and neuronal synaptic proteins (Topinka and Bredt, 1998; Yamazaki et al., 2001; Hering et al., 2003) require S-acylation for their localization to lipid rafts.

S-acylation is neither necessary nor sufficient for lipid raft localization. For example, the anthrax toxin receptor tumor endothelial marker 8 (TEM8) is acylated on several cysteine residues, and acylation functions to exclude the protein from rafts (Abrami et al., 2006). Caveolin-1 is acylated on three cysteines, but these modifications are not necessary for its localization to caveolae, a specialized lipid raft (Dietzen et al., 1995). Members of the Src family kinases are excluded from lipid rafts when S-acylated with polyunsaturated fatty acids (Liang et al., 2001). One of the patterns that are associated with lipid raft recruitment of target proteins is dual palmitoylation in addition to myristoylation or prenylation. In the case of single-pass transmembrane proteins, the length and surface area of the transmembrane domain and their S-acylation state can be used to reliably predict their lipid raft affinity (Lorent et al., 2017). Another factor that was shown to regulate the enrichment of S-acylated proteins in membrane domains is membrane curvature (Larsen et al., 2015). However, many other factors, including the type of lipid added and its interaction with other proteins, contribute to the association of acylated proteins with lipid rafts. Therefore, the specific effects of S-acylation on membrane partitioning should be analyzed in each individual case.

\section{Trafficking}

Protein trafficking is a highly regulated process to ensure that proteins are targeted to the correct cellular location for function (Mellman and Nelson, 2008). Many proteins that are transported between the Golgi, plasma membrane, and the endosomal recycling system require S-acylation for trafficking to their designated location [reviewed in Diaz-Rohrer et al. (2014)]. One example is the soluble N-ethylmaleimide-sensitive factor attachment protein receptors (SNAREs), which are responsible for fusion of membranes at different cellular locations (Jahn and Scheller, 2006). The synaptic-associated protein of $25 \mathrm{kDa}$
(SNAP25) is one of the SNARE proteins that regulate synaptic vesicle exocytosis, and it has four acylation sites (Gonzalo et al., 1999). In addition to membrane attachment, the acylated cysteines determine the distribution of SNAP25 among the trans-Golgi network (TGN), plasma membrane, and the recycling endosomes (Greaves and Chamberlain, 2011). Specifically, decreasing the number of cysteines leads to SNAP25 accumulation in the TGN and recycling endosomes. Interestingly, increasing the number of SNAP25 acylation sites enhances their association with cholesterol-rich membranes in vitro (Salaün et al., 2005). It is proposed that vesicle budding occurs at lipid-raft like regions in the TGN during anterograde trafficking and recycling endosome membranes when recycling proteins back to the plasma membrane (Patterson et al., 2008; Diaz-Rohrer et al., 2014). Therefore, SNAP25 acylation laterally segregate the protein in membrane subdomains to prepare for their exit from the TGN or recycling endosomes and the subsequent delivery to the plasma membrane.

In polarized cells where proteins are delivered to specialized subcellular compartments such as axons and dendrites in neurons, S-acylation can target proteins to their destinations. One example is the glutamic acid decarboxylase 65 (GAD65), which synthesizes the inhibitory neurotransmitter gamma-amino butyric acid (GABA) (Baekkeskov et al., 1990). GAD65 is palmitoylated at two cysteines in the $\mathrm{N}$-terminal domain, and the palmitoylation state does not affect its membrane anchoring at the Golgi apparatus (Shi et al., 1994). Instead, S-acylation of GAD65 is important for its trafficking to the presynaptic sites of axons (Kanaani et al., 2002). Specifically, S-acylation excluded GAD65 from the cis-Golgi face and moved them to the transGolgi membrane (Kanaani et al., 2008). S-acylation is also required for sorting GAD65 into giant axonal vesicles at TGN where it co-localizes with Rab5a, a GTPase that regulates vesicle motility on microtubules (Kanaani et al., 2004). The mechanisms by which S-acylated GAD65 interacts with Rab5a or other components of giant axonal vesicles remain to be explored. Interestingly, de-acylated GAD65 can be recycled back to the Golgi via a non-vesicular pathway, suggesting dynamic regulation at the axonal terminal (Kanaani et al., 2008).

Transmembrane proteins such as ion channels (Hayashi et al., 2005; Hayashi et al., 2009) and transporters (Ren et al., 2015; Du et al., 2017), as well as peripheral proteins such as Ras GTPases (Hancock et al., 1989) rely on S-acylation for localizing to different subcellular locations. Majority of the PAT enzymes that S-acylate target proteins are localized to the Golgi, where newly synthesized proteins are sorted and distributed. Therefore, it is not surprising that $\mathrm{S}$-acylation serves as an important signal for protein trafficking. For example, S-acylation of anterograde cargo proteins such as vesicular stomatitis virus G (VSVG) protein and transferrin receptors facilitates their transport from the cis-to the trans-Golgi (Ernst et al., 2018). However, several PATs are also found at the plasma membrane and ER, where local acylation cycles regulate protein functions (Philippe and Jenkins, 2019). The extent by which such local acylation affect protein trafficking is a topic that is still currently under investigation. 


\section{Protein Interactions}

S-acylation of proteins can regulate their interactions with other proteins and subsequently affect their function. One example is the endoplasmic reticulum (ER)-localized chaperone calnexin, which facilitates the folding of glycoproteins (David et al., 1993). Calnexin is a transmembrane protein with a very large luminal domain and a short cytoplasmic tail. Calnexin has two acylated cysteines at juxtamembrane positions, and acylation is predicted to alter its cytosolic tail orientation (Lakkaraju et al., 2012). S-acylation enables calnexin to interact with the ribosometranslocon complex and the actin cytoskeleton, further stabilizing the supercomplex to ensure chaperone access to protein substrates as they enter the ER lumen (Lakkaraju et al., 2012).

$\mathrm{S}$-acylation of the G-protein coupled receptor $\beta 2$ adrenergic receptor $(\beta 2 \mathrm{AR})$ also regulates its protein interactions. Activation of $\beta 2 A R$ leads to production of cyclic adenosine monophosphate (cAMP). After activation, $\beta$-arrestin binds to the receptor to facilitate receptor internalization and termination of the signal (Dzimiri, 1999). S-acylation of $\beta 2 A R$ at Cys 341 enhances its interaction with phosphodiesterase $4 \mathrm{D}$ and $\beta$-arrestin 2 (Liu et al., 2012). However, the structural properties that are altered by acylation to favor such interactions remain unclear. The $\beta 2 \mathrm{AR}$ can also be acylated at Cys 265, which stabilizes the protein at the plasma membrane after sustained receptor activation (Adachi et al., 2016). Interestingly, acylation at this site is mediated by the Golgi-specific DHHC9/14/18. Inhibiting APT1 blocked stimulusdependent deacylation at Cys 265, suggesting that stimulusdependent regulation of APT1 activity at the plasma membrane is a regulator of $\beta 2 \mathrm{AR}$ signaling.

In neurons, acylation of postsynaptic density protein-95 (PSD95) is crucial for its interaction with cyclin-dependent kinase-like 5 (CDKL-5), which promotes neurite growth and stabilizes synapses (Zhu et al., 2013). It has been reported that acylation of PSD-95 alters the conformation of the protein from a compact to extended conformation (Jeyifous et al., 2016). Therefore, it is possible that the extended conformation of PSD-95 exposes the binding site with CDKL-5. The ability of acylation to regulate protein structure and either directly or through allosteric changes influence protein binding surfaces is now becoming increasingly appreciated, and will be discussed in more detail below.

\section{Protein Half-Life and Stability}

Protein S-acylation can directly influence substrate stability since the absence of S-acylation can lead to decreased half-life of the protein. TBC1 domain family member 3 (TBC1D3) is a plasma membrane protein overexpressed in several human cancers (Pei et al., 2002; Wu et al., 2011). TBC1D3 is acylated on Cys residues 318 and 325 (Kong et al., 2013). When S-acylation of TBC1D3 is inhibited pharmacologically or through mutagenesis, protein half-life is greatly reduced due to increased degradation. The degradation of TBC1D3 is mediated through ubiquitination by E3 ubiquitin ligase cullin-7 (CUL7) and subsequent proteasomal degradation (Kong et al., 2012; Kong et al., 2013). S-acylation deficient TBC1D3 seems to be a preferred substrate for CUL7 (Kong et al., 2013). As such, deacylation of TBC1D3 leads to ubiquitination and proteasomal degradation. The possible protective mechanism by which S-acylation prevents TBC1D3 binding to CUL7 is by sequestering the protein to lipid rafts or by altering its conformation.

Another example of S-acylation regulating protein stability on the plasma membrane is the Fas death receptor (FasR). FasR is a member of the tumor necrosis factor receptor superfamily and represents a canonical death receptor (Ashkenazi and Dixit, 1998). After FasR is activated by its ligand, it starts a cascade of signaling which leads to activation of caspases and eventually to cell death (Kischkel et al., 1995). Fas receptor S-acylation occurs on an intracellular cysteine next to the transmembrane domain, and this modification is necessary to trigger cell death (Chakrabandhu et al., 2007; Feig et al., 2007). FasR S-acylation stabilizes it at the plasma membrane and prevents premature degradation of the receptor. The S-acylation deficient mutant of Fas leads to lysosomal degradation of the protein. FasR activation leads to receptor oligomerization and concentration in lipid rafts. S-acylation of FasR facilitates recruitment to lipid rafts, and subsequent stability of the oligomerized receptor and associated death-induced signaling complex (Rossin et al., 2015).

The unique reversibility of S-acylation allows the cycling of proteins from an S-acylated stable form to deacylated degradation-susceptible protein. In addition to the two examples mentioned above, many other proteins require acylation to prevent their degradation. For example, acylation of C-C motif of chemokine receptor 5 (CCR5) prevents it from entering lysosomal degradation pathways (Percherancier et al., 2001). Another example is the acylation of the yeast SNARE protein Tlg1, which protects it from ubiquitination and degradation (Valdez-Taubas and Pelham, 2005). We are just starting to understand the importance of S-acylation in maintaining protein homeostasis through various protein degradation pathways. Future studies should focus on acylation as a key component of the quality control network and explore its potential roles in disease-associated protein aggregation.

\section{Protein Conformation}

Conformational changes are an integral part of protein function, regulating protein and ligand binding, localization, and stability. By studying a synthetic hydrophobic peptide which is reconstituted into liposomes, it was shown that S-acylation can change the orientation of transmembrane domains (Joseph and Nagaraj, 1995), which is consistent with modeling studies (Morozova and Weiss, 2010). This is of importance since most acylation sites in transmembrane proteins are adjacent to the membrane (Charollais and Van Der Goot, 2009; Morozova and Weiss, 2010). One particularly dramatic example on how S-acylation can regulate membrane protein conformation is exemplified by lipoprotein receptor related protein 6 (LRP6). LRP6 is a type I membrane protein synthesized with an $\mathrm{N}$-terminal signal sequence which targets it to the ER (Hsieh et al., 2003). LRP6 maturation and exit from the ER involves S-acylation to ensure correct folding and orientation of the transmembrane domain. S-acylation of Cys-1394 and Cys1399 changes the length of the hydrophobic stretch of the transmembrane domain and thus alleviating the hydrophobic 
mismatch with the thickness of the ER membrane. Mutation of the S-acylation sites leads to retention of LRP6 in the ER. Newly synthesized LRP6 is also ubiquitinated. Instead of being degraded, ubiquitinated LRP6 is recognized by cytosolic chaperones to promote folding, and once folded it is deubiquitinated (Feldman and van der Goot, 2009). Once properly folded and S-acylated, LRP6 exits the ER and transits through the Golgi before arriving at the plasma membrane where its signaling role takes place (Abrami et al., 2008). The current model of LRP6 maturation is sequential ubiquitination, folding, and S-acylation before the mature protein can exit the ER (Perrody et al., 2016).

Another example how S-acylation regulates protein conformation is the MHV-A59 murine coronavirus spike protein that executes viral cell entry functions. Cell entry requires major conformational changes of the spike protein (Zelus et al., 2003). The spike protein cytosolic tail from several coronaviruses has a cysteine-rich tail adjacent to the cytosolic surface of the transmembrane domain. The tail of the Mouse Hepatitis Virus (MHV) spike protein is extensively S-acylated (Thorp et al., 2006). In spike mutants lacking all three $\mathrm{S}$-acylated cysteine residues, the spike protein remained in the transitional folding state almost 10 times longer than the wild type protein (Shulla and Gallagher, 2009). Moreover, acylationdeficient spike mutants failed to incorporate into secreted virions efficiently, and those few that managed to get into virions cannot support virus-cell entry and fusion efficiently because they are slow to refold into post fusion forms. S-acylation is required for virus spike proteins to unfold into the pre hairpin state at cell surfaces, immediately after binding cell surface receptors. For those viruses without $\mathrm{S}$-acylated spike proteins, this pre hairpin structure remains as viruses enter endosomes, and are then cleaved away by endosomal proteases. These findings indicate S-acylation of the cytosolic tail can anchor spike protein onto virion membranes. S-acylation is required for maintaining metastable prefusion spike conformations and for the progression through conformational changes during infection (Shulla and Gallagher, 2009). Other coronavirus spike proteins are subject to acylation of the cytosolic tail, including SARS-CoV (Petit et al., 2007). Similar to MHV, SARS-CoV spike protein acylation is critical for S-mediated cell fusion. SARS-CoV-2 also has a cysteine-rich cytosolic domain, however whether this domain is acylated has not been investigated. Since low doses of acylation inhibitors such as 2-bromopalmitate profoundly inhibit coronavirus infectivity (Thorp et al., 2006), this is an important and timely area for further study.

Conformational changes in proteins can be influenced by cell signaling events. The emerging roles of dynamic S-acylation in eukaryotic cells highlight the potentially important role of this modification in regulating protein conformation in response to cellular stimuli. It will be of particular interest to study the kinetics of S-acylation in relation to subsequent molecular and cellular events. For example, by using fluorescence resonance energy transfer (FRET) in live cells, it was recently found that the dynamic palmitoylation of sodium-calcium exchanger 1 (NCX1) leads to rearrangement of the f-loop region and regulate its dimerization (Gök et al., 2020). These acylation-induced changes are key in recruiting the exchange inhibitory peptide and mediating $\mathrm{Ca}^{2+}$ influx. Another key regulator of action potentials, the voltage-gated sodium channel $\mathrm{Na}_{\mathrm{v}} 1.5$, also requires S-acylation for its function (Pei et al., 2016). It has been shown that $S$-acylation-induced conformational changes are important for its activation and the excitability of cardiac cells.

\section{METHODS OF DETECTING S-ACYLATION}

\section{Radiolabeling}

Various techniques have been developed to detect protein S-acylation. Each technical approach has their own advantages, limits, and applications (Table 1). The earliest method developed was metabolic labeling with radioactive isotope-labeled palmitic acids, followed by immunoprecipitation of selected target protein and using autoradiography to detect the labeled fatty acid (Schlesinger et al., 1980; Bizzozero, 1995; Caron, 1997). Metabolic labeling with radiolabeled palmitate has been used to effectively identify S-acylated proteins and detect the residence half-life of either palmitate on a specific protein or a palmitate turnover. ${ }^{14} \mathrm{C}$-, ${ }^{3} \mathrm{H}$-, and ${ }^{125} \mathrm{I}$-labeled palmitates were all used in various studies, but ${ }^{3} \mathrm{H}$-palmitate is the most common due to its low cost, safety, and wide availability (Ducker et al., 2006; Kenworthy, 2006; Veit et al., 2008). Despite its wide application in many studies for years, the disadvantages of radiolabeling include low sensitivity, long exposure time (days to weeks), and the hazards associated with the use and disposal of radioactive material.

\section{Click Chemistry-Based Labeling}

"Click chemistry" is a general term to describe simple, high yield, chemical reactions (Kolb et al., 2001). One click chemistry reaction is the copper-catalyzed cycloaddition reaction between azide and alkyne groups (Kolb and Sharpless, 2003). This reaction and related cycloaddition reactions are useful to interrogate biological systems because alkynes and azides are biologically inert [bioorthogonal; Devaraj (2018)]. Click chemistry with alkyne-conjugated lipids was developed to facilitate the detection and purification of acylated proteins (Figure 1A). Synthetic fatty acid analogues with alkyne groups at the terminal end furthest away from the carboxyl group ( $\omega$-position) are incorporated into live cells by metabolic labeling similar to the radiolabeling approach (Hannoush and Sun, 2010). Cells are then lyzed or fixed, and the synthetic lipids incorporated into proteins are subjected to a copper-catalyzed reaction with azide-conjugated probes such as fluorophores or biotin (Wang et al., 2003). Click chemistry-based probes are particularly useful in studies examining the selectivity of incorporation of different fatty acid groups (Greaves et al., 2017).

Brief exposure of alkyne-labeled lipids to live cells permits investigation of the acylation dynamics of newly acylated proteins similar to a classic "pulse-chase" experiment done with radioactivity (Zhang et al., 2010; Martin et al., 2011). There are some caveats to using this approach. 17-Octadecynoic acid is an alkyne probe frequently used to label S-acylated cysteines. However, it can also be processed with low efficiency at $\mathrm{N}$-myristoylation sites (Martin and Cravatt, 2009). In addition, 
TABLE 1 | Comparison of different methods detecting S-acylation. Selected methods are listed above with their targets, advantages, and disadvantages.

\begin{tabular}{|c|c|c|c|}
\hline Method & Target & Advantages & Disadvantages \\
\hline Radiolabeling & $\begin{array}{l}\text { Cells, purified } \\
\text { protein }\end{array}$ & - & $\begin{array}{l}\text { 1. Long exposure time (days to weeks) } \\
\text { 2. Use of radioactive material } \\
\text { 3. Only detect protein palmitoylation }\end{array}$ \\
\hline Click chemistry based labeling & Cells & $\begin{array}{l}\text { 1. High detection sensitivity } \\
\text { 2. Convenient experiment procedure } \\
\text { 3. High specificity } \\
\text { 4. Allow protein pull down } \\
\text { 5. Allow to study the dynamics of protein } \\
\text { S-acylation }\end{array}$ & $\begin{array}{l}\text { 1. Only detect proteins that are palmitoylated during } \\
\text { experiment } \\
\text { 2. May interfere metabolism of cells } \\
\text { 3. Efficiency of probes incorporated onto substrates } \\
\text { varies }\end{array}$ \\
\hline Acyl-biotin exchange based assay & Cells, tissues & $\begin{array}{l}\text { 1. Higher specificity } \\
\text { 2. Detect S-acylation in a steady level } \\
\text { 3. Enable mass spectrometry-based analysis } \\
\text { 4. Allow protein pull down } \\
\text { 5. Show the relative amount of protein in each } \\
\text { acylation state }\end{array}$ & $\begin{array}{l}\text { 1. Possible false-positive results } \\
\text { 2. Require time course to study dynamic S-acylation }\end{array}$ \\
\hline Spectrum counting & Cells & $\begin{array}{l}\text { 1. Simpler sample preparation } \\
\text { 2. Direct comparison of multiple samples }\end{array}$ & $\begin{array}{l}\text { Requires samples prepared and analyzed } \\
\text { separately }\end{array}$ \\
\hline $\begin{array}{l}\text { Stable isotope-labeled peptide with mass } \\
\text { spectrometry }\end{array}$ & Cells & $\begin{array}{l}\text { 1. Minimizes quantitative errors } \\
\text { 2. Increased reproducibility, accuracy, and } \\
\text { sensitivity } \\
\text { 3. Reduce the spectral complexity } \\
\text { 4. Double verification for the identified peptides }\end{array}$ & $\begin{array}{l}\text { Some S-acylated peptides cannot be quantified } \\
\text { (SILAC) }\end{array}$ \\
\hline
\end{tabular}

proteins with a glycosylphosphatidylinositol (GPI) anchor can also be labeled with palmitic acid probes (Jones et al., 2012; Wright et al., 2014). Click chemistry has led to many important discoveries in protein S-acylation, but the efficiency of incorporating alkyne conjugated probes onto substrates are different, thus is not the best choice for unbiased proteomic studies in native tissues. Finally, feeding exogenous lipids to cells leads to significant direct and indirect effects on cellular physiology, and as such both radiolabeling and click chemistry approaches need to be interpreted with caution.

\section{Acyl-Group Exchange-Based Assay}

Acyl-biotin exchange (ABE) is a method based on the in vitro exchange of thioester-linked lipids attached to cysteines to derivatives of biotin (Figure 1B). There are three main steps: 1) irreversible blocking of all the free cysteines by alkylating reagents, often with N-ethylmaleimide or S-Methyl methanethiosulfonate; 2) selective cleavage in S-acylated thioester bonds using neutral hydroxylamine solution; and 3) biotinylation of the newly exposed thiol groups using sulfhydrylreactive biotin such as $\mathrm{N}$-[6-(biotinamido)hexyl]-3'-(2'pyridyldithio) propionamide (biotin-HPDP) followed by streptavidin pulldown (Drisdel and Green, 2004; Drisdel et al., 2006; Wan et al., 2007). The enriched proteins of interest can subsequently be released from the biotin/streptavidin matrix with reducing agents. S-acylated proteins can then be detected by immunoblotting or identified by mass spectrometry.

As an alternative to biotin binding, the newly exposed protein thiol groups from step 2 after hydroxylamine treatment can be directly captured by sulfhydryl-reactive solid phase carriers (Forrester et al., 2011; Kumar et al., 2016) or magnetic microspheres conjugated to sulfhydryl-reactive compounds
(Figure 1B) (Zhang et al., 2018). This alternative method is called Acyl resin-assisted capture (Acyl-RAC) assay. Interestingly, our group and others have found that $\mathrm{ABE}$ and Acyl-RAC are not always equally efficient in detecting all S-acylated proteins (Edmonds et al., 2017). Therefore, it is useful to try both methods when attempting to identify whether a protein-of-interest is S-acylated. In addition, PEG of various sizes can be used to react with free sulfhydryls generated in step 2 instead of biotin. This method is known as the acyl-PEG exchange assay (Howie et al., 2014; Percher et al., 2016). In this method, PEGylation gives a mass shift that can be detected by SDS-PAGE and western blot. Acyl-PEG exchange can not only quantify the number of acylation sites, but also show the relative amount of protein in each acylation state. In our experience, Acyl-PEG exchange is useful for some substrates but not for others. It is not known why some proteins are resistant to PEGylation at cysteine residues, but it may be related to steric constraints.

Acyl-group exchange methods can be applied to various protein samples, including cells (Chen et al., 2020) and tissues (Brigidi and Bamji, 2013) to detect S-acylation. They provide a higher specificity compared to metabolic labeling by limiting the capture to only hydroxylamine-sensitive thioester bonds, without capturing proteins from other functional groups. Perhaps most importantly, Acyl-group exchange detects proteins modified by endogenous lipids, which is a significant advantage over radiolabeling and click chemistry approaches. One significant disadvantage is that this method cannot discriminate what type of lipid was conjugated to the cysteine residue. It is also important to verify bone fide substrates using controls such as reactions without hydroxylamine treatment and mutagenesis to confirm the cysteine residue(s) being modified. Additionally, thioester 


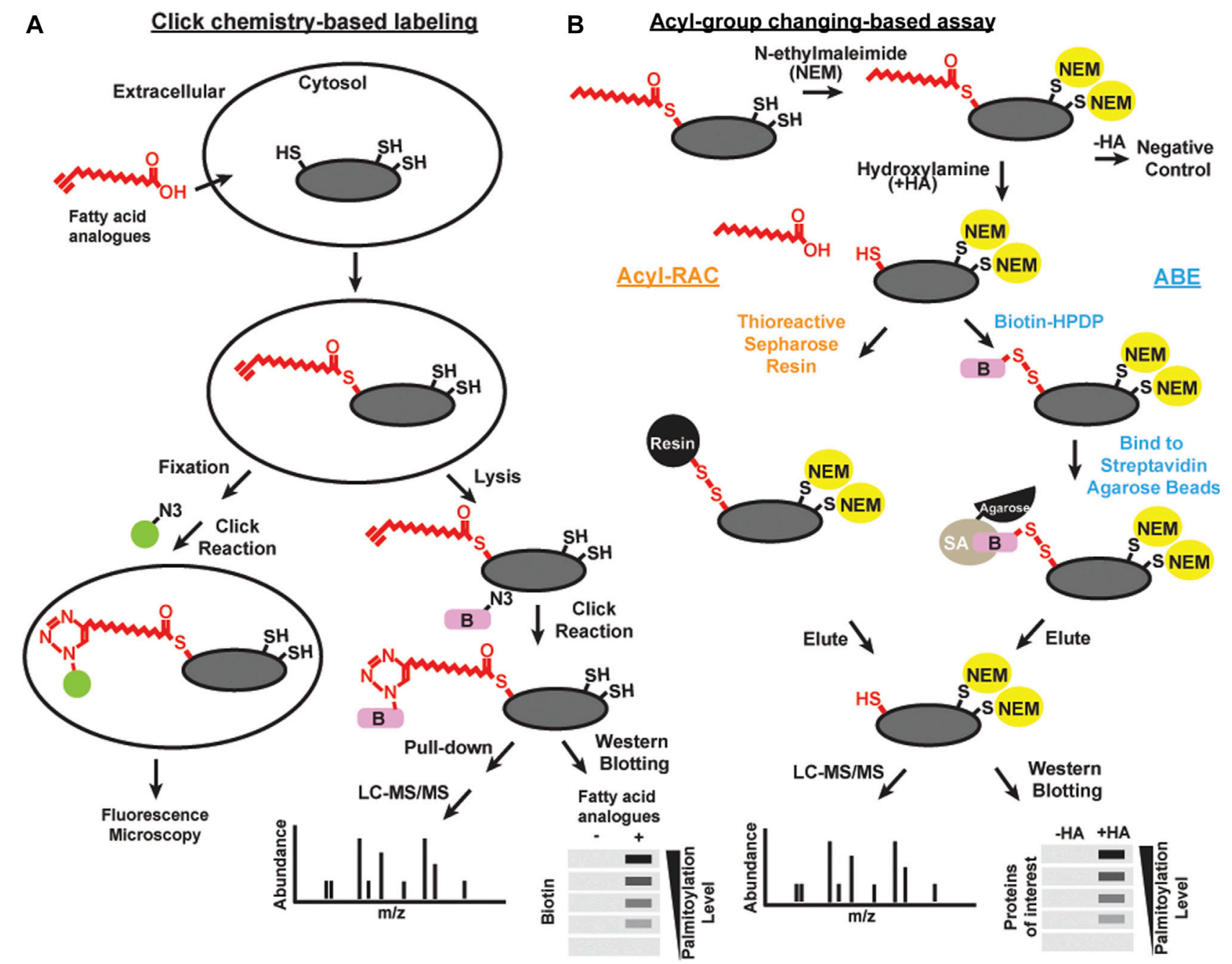

FIGURE 1 | Schematics of methods of detecting acylation Click chemistry-based labeling (A) and acyl-group changing-based assay (B) can be combined with various detection methods, including microscopy, liqued chromatography and tandem mass spectrometry (LC-MS/MS), and western blotting, to detect S-acylated proteins.

bonds are also present in non-S-acylated proteins, including multiple members of the mitochondrial pyruvate dehydrogenase complex, the ubiquitin conjugating enzymes, and the active site intermediate of glyceraldehyde 3-phosphate dehydrogenase (GAPDH) (Roth et al., 2006; Wolfson-Stofko et al., 2013). Therefore, acyl-group exchange methods can lead to false positive results. It is also worth noting that acyl-group exchange methods provide snapshot-like profiles of S-acylated proteins at a given time point. Our group and others used these methods over a time course to evaluate the dynamic S-acylation (Chen et al., 2020; Shayahati et al., 2020).

\section{Proteomics}

S-acylation proteomics can be achieved by performing metabolic labeling, ABE, or acyl-RAC followed by mass spectrometry. When using metabolic labeling, click chemistry is used to attach azide-conjugated biotin to the alkyne-conjugated lipid moieties incorporated onto proteins (Martin and Cravatt,
2009; Yount et al., 2010; Gao and Hannoush, 2014; Gao and Hannoush, 2014). Then acylated proteins can be enriched and analyzed using liquid chromatography and tandem mass spectrometry (Figure 1). Similarly in ABE or acyl-RAC procedures, proteins are eluted using reducing agents and analyzed using mass spectrometry. The relative abundance of proteins is estimated by using spectral counting (Old et al., 2005). Such approaches have been used to identify novel acylated protein substrates in different species and cell types (Roth et al., 2006; Martin and Cravatt, 2009; Nievas et al., 2018). By digesting the proteins at various steps before mass spectrometry, ABE or Acyl-RAC-based studies can also be used to identify the specific sites of acylation [reviewed in Wang and Yang (2021)]. Our group and others have successfully used proteomic approaches to compare the acylation proteome between samples, for example stimulated versus resting cells (Colquhoun et al., 2015; Sobocinska et al., 2018). With increasing evidence suggesting that $\mathrm{S}$-acylation is highly 
dynamic, comparative proteomic studies can be especially useful in globally examining the temporal changes of S-acylation levels of signaling proteins.

One recently developed method to quantitatively compare the S-acylation profiles across two samples uses stable isotope labeling by amino acids in cell culture (SILAC) (Ong et al., 2002). Cells are first labeled with heavy or light isotope containing amino acids, mixed to minimize systemic errors, and then the acylated proteins from each sample are enriched using metabolic labeling (Martin et al., 2011) or ABE (Zhang et al., 2018). The heavy and light mass tags can be separated with mass spectrometry analysis and the relative abundance of S-acylation from two samples can be compared. SILAC has been used in several applications, including comparing the acylation proteomes of neuronal stem cells from wild-type and DHHC5 deficient mice, providing a list of 20 potential DHHC5 substrates (Li et al., 2012). In another study, two hepatocellular carcinoma cell lines with different metastasis potentials were examined and 151 proteins were identified to be differentially acylated (Zhang et al., 2018). Another improvement of SILAC was developed recently using three isotopes to allow more samples to be processed at the same time (Clark et al., 2016). This method can be potentially used to compare the acylation proteomes from more samples. Recently, $\mathrm{ABE}$ and stable isotope labeling in the whole animal (SILAM) were combined to look at Huntington's disease (HD) by profiling S-acylation change in two mouse mutants (Wan et al., 2013). This approach shows promise in identifying the S-acylated proteome in animal models of human disease.

\section{ENZYMATIC REGULATORS OF S-ACYLATION \\ Palmitoyl-Acyl Transferases (PATs): From Yeast to Human}

The enzymes that catalyze the transfer of acyl groups to cysteines on substrate proteins were first discovered in yeast (Lobo et al., 2002; Roth et al., 2002; Mitchell et al., 2006). Erf2, in the presence of Erf4, was described as a PAT that palmitoylates Ras (Bartels et al., 1999; Lobo et al., 2002). Later studies identified multiple proteins in this family, including the Huntingtin interacting protein 14 (HIP14) (Huang et al., 2004), Golgi-specific zinc finger protein (GODZ) (Keller et al., 2004), and Swf1 (ValdezTaubas and Pelham, 2005). They share the conserved amino acid sequence $\mathrm{D}-\mathrm{H}-\mathrm{H}-\mathrm{C}$ in a cysteine rich catalytic domain, leading to the nomenclature DHHC enzymes.

There are 23 PATs in human, which are encoded by the zincfinger aspartate-histidine-histidine-cysteine ( $Z D H H C)$ genes 1 to 24 (there is no ZDHHC10 gene) (Korycka et al., 2012). We will refer to these proteins as DHHC enzymes for the rest of this review. DHHC enzymes have tissue specific expression patterns (Fukata et al., 2006; Ohno et al., 2006). The majority of the DHHC enzymes localize to the Golgi membrane, however they can be retained in the ER or trafficked to the plasma membrane (Ohno et al., 2006). DHHC4 and DHHC6 have lysine-based sorting signals that retain them in ER membranes (Gorleku et al., 2011).
DHHC2, 3, 5, 7, 8, 20, and 21 have been shown to traffic to the plasma membrane (Fernández-Hernando et al., 2006; Ohno et al., 2006; Akimzhanov and Boehning, 2015; Chen et al., 2019). All mammalian DHHC enzymes have at least four transmembrane domains with the DHHC motif in the cytosol [reviewed in Tabaczar et al. (2017)]. It is worth noting that the yeast PATs Akr1, Akr2, and Pfa5 have DHYC, and DHHC13 has DQHC at the conserved DHHC domain (Mitchell et al., 2006). However, mutation of the first His in Erf2 abolished its ability to acylate Ras (Lobo et al., 2002). Additionally, mutation of the Asp-His in Akr2 abolished its autoacylation as well as acylation of its substrate Yck2 (Roth et al., 2002). These studies indicate that the conserved DHHC motif is crucial for the enzymatic reaction.

Later studies found that autoacylation of the cysteine residue at the conserved DHHC domain serves as a reaction intermediate, suggesting a two-step ping-pong mechanism for DHHC enzymes (Mitchell et al., 2010; Jennings and Linder, 2012). Interestingly, the yeast PATs Swf1 and Pfa4 showed only partial loss of activity when the catalytic cysteine was mutated to arginine, suggesting the possibility of a direct nucleophilic attack on palmitoyl-CoA by the substrate (González Montoro et al., 2015). Despite the relatively conserved cysteine-rich domain around the catalytic core, whether individual PAT can have different enzymatic reaction mechanisms remains unclear.

The recently solved human DHHC20 and zebrafish DHHC15 crystal structures showed details about the organization of the DHHC active site (Rana et al., 2018). The cysteine-rich domain between the second and the third transmembrane domain associates with two zinc ions, which are important for positioning the active site. The aspartic acid and the histidines in the conserved DHHC motif position the cysteine for nucleophilic attack. The catalytic cysteine points toward the lipid bilayer, enabling the formation of reaction intermediate that inserts the acyl chain into the hydrophobic lipid bilayer. Another highly conserved motif in DHHC PATs is the Thr-Thr$\mathrm{x}$-Gly (TTxE) motif in the C-terminal tail right after the forth transmembrane domain (Mitchell et al., 2006). The TTxE motif is in close contact with the DHHC active site, and the second threonine forms a hydrogen bond with the aspartic acid of the active site (Rana et al., 2018). These features of the various conserved domains all contribute to the enzymatic reaction of DHHC proteins.

\section{Protein Substrate Recognition}

All DHHC enzyme family members have distinctive $\mathrm{N}$ - and C-termini that are implicated in substrate recognition. There are several protein-protein interaction motifs unique to individual DHHC proteins. DHHC13 and 17 both have ankyrin repeats in the $\mathrm{N}$-terminal region before the first transmembrane domain, and this domain functions to bind to the Huntingtin protein in neurons (Huang et al., 2004). When fusing the ankyrin repeats to the N-terminus of DHHC3, which is not a PAT for Huntingtin, the chimeric protein was able to palmitoylate Huntingtin and regulate its trafficking (Huang et al., 2009). Another example is the PSD-95/Discs-large/ZO-1 homology (PDZ) binding motif in the C-terminal tail of DHHC5/8. Binding and palmitoylation of the neuronal protein 
glutamate receptor interacting protein (GRIP1b) require the PDZ binding motif on DHHC5/8 (Thomas et al., 2012). This motif in also required for the interaction of DHHC5 with the synaptic scaffold protein PSD-95 (Brigidi et al., 2015). Not surprisingly, regions other than the well-characterized protein-protein interaction domains on DHHC enzymes can also be important for substrate recognition. In the very large 700 amino acid C-terminal tail of DHHC5, a 120 amino acid region right after the transmembrane domain, but not the PDZ domain, is crucial for recognition and palmitoylation of phospholemman (Howie et al., 2014).

Certain domains or amino acids on the substrates also affect recognition by specific DHHC enzymes. The yeast vacuolar protein Vac8 is palmitoylated by the yeast PAT Pfa3 in the N-terminal Src homology 4 (SH4) domain (Smotrys et al., 2005). Removing the C-terminal region after the SH4 domain of Vac8 enabled it to be palmitoylated by four additional PATs (Nadolski and Linder, 2009). In some cases, change in a single amino acid on the substrate protein can affect its recognition by DHHC enzymes. For example, the SNARE proteins SNAP25 and SNAP23 are structurally similar yet are not acylated by the same set of DHHC enzymes. SNAP25 can be S-acylated by DHHC15 but SNAP23 cannot. Mutation of Cys-79 of SNAP23 to mimic SNAP25 promoted its palmitoylation by DHHC15 (Greaves et al., 2010). The Cys mutation of SNAP23 may increase the direct interaction with $\mathrm{DHHC15}$, or may promote membrane affinity and thus increase the likelihood of association with DHHC15. It is clear that the interaction between substrates and DHHC are regulated by various components. Therefore, studies mutating regions on both the DHHC enzyme and substrates for each substrate-DHHC pair will enable us to further understand PAT substrate recognition mechanisms. There is currently no way to predict which DHHC enzymes are responsible for the acylation of a specific protein. Recent advances in quantitative proteomic approaches can give us more answers by comparing cells with and without each of the DHHC enzymes.

\section{Lipid Substrate Specificity}

DHHC proteins transfer the fatty acyl groups from acylcoenzyme A (acyl-CoA) to protein substrates (Huang et al., 2004). The lipid substrate specificity was first studied for yeast Erf2/Erf4 complex by using unlabeled fatty acyl-CoA to compete with radiolabeled palmitoyl-CoA in vitro (Lobo et al., 2002). They found that shorter chain length such as lauryl (12-carbon) and myristoyl (14-carbon) showed weak inhibition, whereas 16 and 18-carbon saturated or unsaturated acyl-CoAs showed effective inhibition. Similar competition assay using 14-20-carbon saturated and unsaturated fatty acyl-CoAs were also used for studying DHHC2 and DHHC3 proteins (Jennings and Linder, 2012). It was found that all acyl-CoAs with longer than 14 carbons efficiently inhibited DHHC2 in vitro activity, whereas long chain fatty acyl-CoAs with 18 and 20 carbons showed minimal inhibition of DHHC3 activity. They also observed reduced rate of both autoacylation of DHHC3 and acyl group transfer to substrate when the 18-carbon stearoyl-CoA was used instead of the 16-carbon palmitoyl-CoA. These studies suggested that DHHC enzymes in general can incorporate a wide variety of fatty acyl chain lengths, but each enzyme has different degrees of lipid substrate selectivity. Extensive work has also been done to characterize the fatty acid selectivity in the highly similar DHHC3 and DHHC7 (Greaves et al., 2017). Through a series of domain swapping and point mutation experiments, one single amino acid in the third transmembrane domain of DHHC3 is shown to be crucial for its preference for shorter-chain fatty acids.

The crystal structures of human DHHC20 and zebrafish DHHC15 provided more insight into the mechanisms of lipid substrate selectivity (Rana et al., 2018). Both structures showed a hydrophobic cavity in which fatty acyl-CoA can be inserted into. All four transmembrane domains can interact with the acyl chain, and mutations of multiple highly conserved residues lining the cavity caused loss of enzymatic activity. In DHHC20, the tapered end of the cavity is sealed off by a hydrogen-bound between a Tyr and a Ser residue. Mutating the Tyr to the less bulky Ala caused an increased enzymatic activity using short-chain acyl-CoA. And mutating the Ser to the bulkier Phe shifted the preference toward long-chain acyl-CoA. These data suggested that the diversity of the amino acids lining the acyl chain binding cavity of different DHHC enzymes contribute to the differential lipid substrate selectivity observed (Rana et al., 2018).

\section{S-Acylation Cascades}

Multiple DHHC enzymes have S-acylated residues outside of the autoacylated catalytic core. A proteomic study in a human prostate cancer cell line showed that DHHC5, 6, and 8 are acylated at three cysteines C-terminal to the DHHC catalytic core (Yang et al., 2010). It was proposed that S-acylation of DHHC5 causes conformational changes to allow substrate selection. Another study expanded the list of acylated DHHC enzymes to also include DHHC 16, 17, and 20 (Collins et al., 2017). In HeLa cells, acylation of the DHHC5 C-terminal tail is important for its interaction with substrate Golga7b, which subsequently stabilizes DHHC5 at the plasma membrane (Woodley and Collins, 2019). Our group found that in cardiomyocytes, the C-terminal tail of DHHC5 became acylated following beta-adrenergic stimulation (discussed in detail below) (Chen et al., 2020). It is worth noting that in our study, we found that the acylation of the DHHC5 C-terminal tail did not affect its autoacylation at the catalytic core. One recent study showed that DHHC20 can S-acylate the DHHC5 C-terminal tail and regulates its ability to interact with the Na pump (Plain et al., 2020).

One study reported a palmitoylation cascade in which DHHC16 palmitoylates three cysteines sites on the C-terminal tail of DHHC6 (Abrami et al., 2017). They found that the palmitoylation state of DHHC6 affected its degradation, localization within the ER membrane, and activity. The depalmitoylation of DHHC6 is catalyzed by APT2, which itself is acylated and activated by a yet-to-be-identified DHHC enzyme (Kong et al., 2013). These examples suggest that there are complex acylation/deacylation networks involving multiple DHHC and APT enzymes. The discoveries of acylation cascades marks one way by which we can start to understand the regulatory mechanisms of DHHC enzyme function. DHHC enzymes can also be regulated through post-translational 
TABLE 2 | Summary of DHHC enzymes and human diseases. DHHC enzyme alterations in human diseases, including cancers and neurological diseases.

\begin{tabular}{|c|c|c|c|c|}
\hline DHHC enzyme & Diseases & Alterations in DHHC & Related DHHC substrates & References \\
\hline 2 & Gastric adenocarcinoma, Hepatocellular carcinoma & Reduced expression & CD9, CD151, CKAP4 & $175,176,183$ \\
\hline 3 & Breast cancer & Up-regulated & ERGI3 & 177 \\
\hline 5 & Non-small cell lung cancer & Activated & Unidentified & 178 \\
\hline 8 & Epilepsy, Schizophrenia & Increased expression, Genetic polymorphisms & Unidentified & 184,185 \\
\hline 9 & X-linked intellectual disability & Loss of expression & Unidentified & 186 \\
\hline 11 & Bladder cancer & Increased copy number & Unidentified & 179 \\
\hline 14 & Gastric cancer, Leukemia & Increased expression, Activated & Unidentified & 180 \\
\hline 15 & X-linked intellectual disability & Loss of expression & Unidentified & 186 \\
\hline 17 & Glioblastoma & Up-regulated & $\mathrm{H}$ - and $\mathrm{N}$ - Ras & 238 \\
\hline
\end{tabular}

modifications such as phosphorylation (Lievens et al., 2016), or their expression can be regulated through microRNAs (Chai et al., 2013). Therefore, when studying the S-acylation of a substrate protein, one must take into consideration the various levels of regulations contributing to the cellular functions and physiological effects.

\section{PATs and Human Diseases}

Multiple DHHC enzymes have been implicated in human disease, including cancer (Table 2). DHHC2 expression is decreased in hepatocellular carcinoma (Peng et al., 2014) and gastric adenocarcinoma (Yan et al., 2013), and it acts as a tumor suppressor in metastasis. DHHC3 is shown to be upregulated in breast cancer, and increased expression correlates with decreased patient survival (Sharma et al., 2017). DHHC5 is suggested to drive oncogenesis in non-small cell lung cancer (Tian et al., 2015). Increased copy numbers of $z D H H C 11$ is implicated in bladder cancer (Yamamoto et al., 2007). DHHC14 overexpression is found in gastric cancer samples (Oo et al., 2014). DHHC enzymes and their substrates can affect the pathophysiology of cancer by regulating cell proliferation, cell migration, and apoptotic signaling [reviewed in Yeste-Velasco et al. (2015), Ko and Dixon (2018)]. For example, DHHC2 promotes cell-cell contact and inhibits epithelial-mesenchymal transition through its substrates CD9 and CD151, two cell surface proteins that regulate cell migration (Sharma et al., 2008). However, given the fact that DHHC2, like all other DHHC enzymes, has a variety of substrates, it is difficult to pinpoint the most critical substrates that contribute to cancer pathophysiology. This is one of several challenges in understanding how each DHHC enzymes contribute to disease pathogenesis.

DHHC enzymes also contribute to neurological disorders. DHHC8 has increased expression in epilepsy patients (Yang et al., 2018), and single-nucleotide polymorphisms (SNPs) in the $z D H H C 8$ gene are associated with susceptibility to schizophrenia (Mukai et al., 2004). Mutations in $z$ DHHC9 are found in some families with X-linked mental retardation (Raymond et al., 2007). DHHC13 and 17 are known to palmitoylate the Huntingtin protein, and mouse models of DHHC13 and 17 show Huntington's disease-like phenotypes (Yanai et al., 2006; Singaraja et al., 2011; Sutton et al., 2013). Many neuronal proteins/processes require protein acylation. DHHC9 promotes dendritic growth and synapse maturation.
It has been shown that defective acylation of the small GTPases Ras and TC10 by DHHC9 contributes to dendritic dysfunction in animal knockout models (Shimell et al., 2019). The DHHC9 knockout mice also have seizure-like events suggesting that acylation by DHHC9 contributes to both intellectual disability and seizure-like disorders. The DHHC9 gene is located on the $\mathrm{X}$-chromosome, and mutations associated with disease include insertions, frameshift mutations, and missense mutations suggesting mechanistically loss of function mutations predominate (Raymond et al., 2007; Mitchell et al., 2014). Female carriers are unaffected.

Many disease-associated proteins are known to require S-acylation for their functions. However, due to the redundancy of DHHC enzyme function and their various expression levels in certain tissues, the disruption of specific DHHC-substrate pairs will likely yield drastically different outcomes depending on the cell type. Therefore, more studies in cell lines and animal models are required to detail the DHHCsubstrate pairs that contribute to disease pathophysiology.

\section{ENZYMATIC REGULATORS OF DEACYLATION}

\section{APT1 and APT2}

Acyl protein thioesterase 1 (APT1) was purified from rat liver cytosol based upon its ability to deacylate $\mathrm{H}$-Ras and Gai in vitro (Duncan and Gilman, 1998). APT1 is a highly conserved $\alpha / \beta$ hydrolase, which contains both a G-X-S-X-G motif common in lipases and esterases and an active site S-H-D catalytic triad (Devedjiev et al., 2000). S-acylated proteins such as Gai are the preferred substrates of APT1 in vitro. Consistent with its role as an acyl-protein thioesterase, overexpression of APT1 increases the basal turnover rate of S-acylated residues on many substrates, including small GTPases (Dekker et al., 2010; Kong et al., 2013), endothelial nitric oxide synthase (Yeh et al., 1999), and a number of other proteins. The neuronal microRNA miR-138 was found to modulate APT1 levels in synaptic spines, which reduce spine volume by decreasing Ga13 S-acylation (Siegel et al., 2009).

In addition to APT1, vertebrates express the paralogous enzyme APT2 (68\% identity, $81 \%$ similarity) (Tomatis et al., 2010). APT1 and APT2 have different substrates. APT1 overexpression has no effect on growth associated protein 43 (GAP43) S-acylation, whereas overexpression of APT2 promotes GAP- 
43 deacylation (Tomatis et al., 2010). In another example, only APT2 is essential for deacylation and stabilization of DHHC6 (Abrami et al., 2017), which is important for efficient S-acylation of the cytoplasmic domains of calnexin and multiple other S-acylated ER proteins. Moreover, agonist-dependent $S$-acylation of the $\beta 2$-adrenergic receptor can only be reversed by APT1, but not APT2 (Adachi et al., 2016). It is still unclear why and how APT1 and APT2 prefer certain substrates in vivo. Peptide library screening in vitro indicates that amino acids surrounding the acylated residue may dictate preference for APT1 or APT2. However, the large overlap in substrate utilization between the two enzymes suggests that there is functional redundancy (Amara et al., 2019).

Perhaps not surprisingly based upon sequence homology, APT1 and APT2 share a lot of similarities in structure and function. Both APT1 and APT2 are members of the serine hydrolase family, which share a characteristic $\alpha / \beta$-hydrolase fold and a hydrophobic cleft that accommodates the acyl chain (Devedjiev et al., 2000). They are broadly expressed in almost all tissues (Bachovchin et al., 2010; Abrami et al., 2017). It is worth noting that APT1 and 2 are primarily cytoplasmic (Yang et al., 2010), but can demonstrate partial internal membrane (Vartak et al., 2014) and plasma membrane (Kong et al., 2013) localization. Both enzymes have a cysteine at the second position after the initial methionine, which can be S-acylated to facilitate membrane localization (Kong et al., 2013; Vartak et al., 2014). APT1 and APT2 cycle on membranes through an acylation/ deacylation cycle where auto-deacylation drives release from membranes into the cytosol compartment (Vartak et al., 2014).

We and others have shown that proteins that are acylated after cellular stimulation are deacylated just as rapidly (Akimzhanov and Boehning, 2015; Chen et al., 2019). This would be expected of a second messenger cascade. Interestingly, the kinetics of deacylation are substrate dependent. As an example, in cardiomyocytes $\mathrm{Ga}$ proteins are rapidly acylated and deacylated, while the inhibitory GPCR kinase GRK2 is acylated more slowly and persistently (Chen et al., 2019). Surprisingly, very little is known about the regulation of APT1 and APT2. In contrast to DHHC enzymes, the genetic diversity of APT enzymes is minimal (at least as we currently understand them). Both APT1 and APT2 are small ( 200aa) soluble proteins with no obvious structural motifs indicative of a regulatory mechanism. It is possible, however, to generate relatively specific chemical inhibitors despite high structural homology (Won et al., 2016), consistent with the observation of peptide substrate specificity (Amara et al., 2019). However, for $\mathrm{S}$-acylation to be a bone fide signaling modification, regulation of the deacylation process should be a prerequisite. Interestingly, we found that APT1 was responsible for turnover of S-acylated groups on Lck under resting conditions, but not after cellular stimulation (Akimzhanov and Boehning, 2015).

\section{ABHD17 and Related Proteins}

Two independent groups found that additional members of the $\alpha / \beta$-hydrolase fold (ABHD) family of serine hydrolases are potent depalmitoylating enzymes for select substrates, including PSD-95 and N-Ras (Lin and Conibear, 2015; Yokoi et al., 2016). ABHD proteins and APTs both belong to the serine hydrolase superfamily and share extensive sequence homology (Long and Cravatt, 2011; Cao et al., 2019). Like APT enzymes, these enzymes are membrane anchored by palmitoylation. They have a unique pharmacological profile, and in particular are inhibited by hexadecylfluorophosphonate (HDFP) but not palmostatin B (Martin et al., 2012; Lin and Conibear, 2015). Deacylation activity against $\mathrm{N}$-Ras was demonstrated for ABHD17A, ABHD17B, ABHD17C (Lin and Conibear, 2015). In addition to N-Ras, it is known that PSD-95 is rapidly deacylated in response to neuronal depolarization. To identify which enzyme deacylates PSD-95, a large functional overexpression screen to identify PSD-95 acyl-protein thioesterases was performed in cell lines (Yokoi et al., 2016; Tortosa et al., 2017). Of 37 tested proteins with putative thioesterase activity, ABHD12, 13, 17A, 17B, 17C, and APT1, 2 were shown to have significant activity for acylated PSD-95. The ABHD enzyme 17A, $17 \mathrm{~B}$, and $17 \mathrm{C}$ had the greatest activity in cell lines and neurons. Over-expression of ABHD17 enzymes reduced synaptic AMPA receptors and $\mathrm{PSD}-95$ clustering in neurons, while the individual knockdown of ABHD17A/B/C stabilized S-acylated PSD-95 and inhibited PSD-95 clustering (Yokoi et al., 2016). Similar to APT1/ 2, ABHD17 enzymes themselves need to be S-acylated for plasma membrane association and to other potential S-acylated protein substrates. The cysteine rich domain in N-terminus is necessary for both S-acylation and plasma membrane association (Martin and Cravatt, 2009). Deletion of the cysteine rich domain in N-terminal has no effect on the activity of ABHD17, suggesting the S-acylation is only necessary for membrane localization but not for enzyme activity.

We are just beginning to understand the role of ABHD17 and related proteins as acyl-protein thioesterases, including structure, function, regulation, and substrate specificity. Recently in a global mutagenesis screen for suppressors of pulmonary metastasis, ABHD17A was identified as one of only eight metastatic suppressors (van der Weyden et al., 2017). The mechanisms by which it performs this function are unknown, but could presumably related to Ras or other oncogenic signaling pathways. Clearly more animal models are required to understand the physiology of this new class of acyl-protein thioesterase. Structural studies are also needed to understand if the $\mathrm{N}$-terminal cysteine rich domain has functional roles in addition to acylation, such as a role in substrate engagement (Martin and Cravatt, 2009). Finally, almost nothing is known about the potential function of other ABHD enzymes that have shown in vitro acyl-protein thioesterase activity, including ABHD6, 12, 13 and 16A (Lin and Conibear, 2015; Yokoi et al., 2016). Recently ABHD10 was shown to localize exclusively in the mitochondria and deacylate the mitochondrial protein peroxiredoxin 5 (PRDX5), a key regulator of the antioxidation machinery (Cao et al., 2019). In addition to APT and ABHD proteins, there are lysosomal palmitoyl protein thioesterases 1 and 2 (PPT1/2), which are involved in protein degradation (Camp and Hofmann, 1993; Camp et al., 1994; Calero et al., 2003). PPTs are not thought to participate in S-acylation signaling events in the cytosol (Verkruyse and Hofmann, 1996), and therefore will not be 
discussed further in this review. It is worth noting that PPT1 deficiency is associated with neuronal ceroid lipofuscinosis, a severe neurodegenerative disease (Vesa et al., 1995). The functions of PPT proteins have been thoroughly reviewed elsewhere (Lu and Hofmann, 2006; Zeidman et al., 2009; Koster and Yoshii, 2019).

\section{DYNAMIC S-ACYLATION/DEACYLATION}

Due to the reversible nature of protein S-acylation, the kinetics and the functional importance of dynamic acylation/ deacylation cycles is a topic of great interest. Traditionally, pulse-chase experiments using radioactively labeled palmitate was used to determine the turnover of S-acylation, including G alpha proteins (Degtyarev et al., 1994) and Ras GTPases (Magee et al., 1987; Baker et al., 2003). However, evidence suggested that the pulse-chase method underestimated the turnover rates and is not sufficient for several reasons to determine the kinetics of cellular events that happens within seconds to minutes (Rocks et al., 2005). The understanding of dynamic S-acylation has been dramatically advanced by using more sensitive techniques, including clickchemistry-based metabolic labeling and acyl exchange methodologies described above. Studies by our group and many others showed that $\mathrm{S}$-acylation is a rapid and reversible process necessary for cell signaling (Akimzhanov and Boehning, 2015; Fukata et al., 2016; Matt et al., 2019; Chen et al., 2020). These findings emphasize the importance of dynamic acylation in signal transduction similar to other post-translational modifications such as phosphorylation. Here we describe three examples of the dynamic acylation/ deacylation cycle, the enzymatic regulators, and the cellular functions.

\section{G Alpha Proteins and Beta-Adrenergic Signaling}

Beta-adrenergic receptors ( $\beta$-ARs) are $G$ protein-coupled transmembrane receptors that transmit extracellular signals to regulate contraction in the cardiomyocytes and other cell types. Unstimulated $\beta$-ARs are bound to heterotrimeric G-proteins, which consist of $\alpha, \beta$, and $\gamma$ subunits. Ligand binding to $\beta$-ARs leads to the exchange of GDP for GTP on the Ga subunit, and as such the receptor acts as a guanine nucleotide exchange factor. Activated $\mathrm{G} \alpha$ and $\mathrm{G} \beta \gamma$ subunits then dissociate and act upon downstream signaling pathways. In the heart, $\beta$-AR signaling has an important role in regulating contraction. Cardiac $\beta$-ARs interact with both Gas and Gai. Several members in $\beta$-AR signaling pathway are S-acylated in cardiomyocytes, such as $\beta 2$ AR, Gas, Gai, and adenylyl cyclase 5/6 (Rybin et al., 2000; Ostrom et al., 2001; Steinberg and Brunton, 2001), and S-acylation of these proteins is crucial for subsequent functions (Thinon et al., 2016; Wedegaertner et al., 1993). The two major sub-types of $\beta$-ARs in mammalian hearts are the $\beta 1-A R$ and $\beta 2$-AR. Both receptors interact with Gas, leading to downstream adenylyl cyclase activation and production of cAMP. Acylation of $\beta-A R$ signaling proteins can lead to enrichment in caveolae, where signaling components assemble as a macromolecular signaling complex (Chen et al., 2020; Essandoh et al., 2020). Caveolae are specialized lipid rafts/membrane microdomains, and function in part to enrich S-acylated proteins important for cellular signaling in the heart (Gratton et al., 2004; Balijepalli et al., 2008).

It has been known for many years that $\beta$-AR stimulation leads to rapid turnover of the S-acylated groups on Gas. The model for stimulus-dependent acylation was based on the availability of free Gas: separation from the $\beta \gamma$ subunits allowed the access of putative S-acylation/deacylation enzymes (Wedegaertner et al., 1993; Degtyarev et al., 1993). We recently showed an alternative mechanism for $\mathrm{Ga}$ acylation that requires stimulusdependent plasma membrane DHHC5 activation (Chen et al., $2020)$. The $\beta 2-A R$ itself is acylated on cysteine 341 . Mutation of this residue results in reduced capacity to couple to adenylyl cyclase and alterations in phosphorylation, trafficking, and recruitment of $\beta$-arrestin 2 and phosphodiesterase (PDE) 4D (Liu et al., 2012; O’Dowd et al., 1989; Moffett et al., 1996). Ultimately, inhibiting $\beta 2$-AR acylation leads to an increased rate of cardiomyocyte contraction (Liu et al., 2012). It has also been shown that Golgi-resident DHHC9/14/18 are redundantly responsible for S-acylation of the $\beta 2-A R$ on cysteine 265, and APT1 is the enzyme for $\beta 2-A R$ deacylation (Adachi et al., 2016). S-acylated $\beta 2$-ARs are retained at the plasma membrane, and under conditions of sustained adrenergic stimulation they are resistant to internalization until deacylated by APT1 (Adachi et al., 2016). For S-acylation of $\mathrm{Ga}$ proteins, it has been shown that DHHC3 and DHHC7 can S-acylate Gaq, Gas, and Gai2 in HEK293T cells (Tsutsumi et al., 2009). However, another study found that stimulation of $\beta$-ARs in cell lines did not induce detectable changes in $\mathrm{Ga}$ protein S-acylation levels (Jones et al., 1997). More recently, our lab found S-acylation levels of both Gas and Gai were increased rapidly following $\beta$-AR stimulation [Figure 2; Chen et al. (2020)]. By $30 \mathrm{~min}$, the S-acylation levels of Gas and Gai were returned to baseline, presumably indicating activation of acyl-protein thioesterases. The agonist-induced S-acylation was required for downstream cAMP production and contractile responses (Chen et al., 2020). Together, there is very strong evidence that stimulus-dependent $\mathrm{S}$-acylation is an essential regulator of $\beta$-AR signaling and downstream modulation of heart contraction.

The DHHC5 enzyme is localized on the cardiomyocytes plasma membrane and enriched in caveolae. DHHC5 can regulate the dynamic S-acylation of phospholemman, a regulatory subunit of the $\mathrm{Na}$ pump, in a stimulus-dependent manner (Tulloch et al., 2011; Howie et al., 2014). Knocking down DHHC5 in cardiomyocytes showed that this enzyme is essential for S-acylation of Gas, Gai, and downstream functional responses of $\beta$-AR stimulation (Chen et al., 2020). Using purified components, an S-acylation assay showed that Gas and Gai are direct substrates of DHHC5. DHHC5 itself is subject to dynamic $S$-acylation, and like the $\beta-A R$, this modification stabilizes the enzyme at the plasma membrane. Importantly, $\mathrm{S}$-acylation of the DHHC5 carboxy-terminal tail is required 


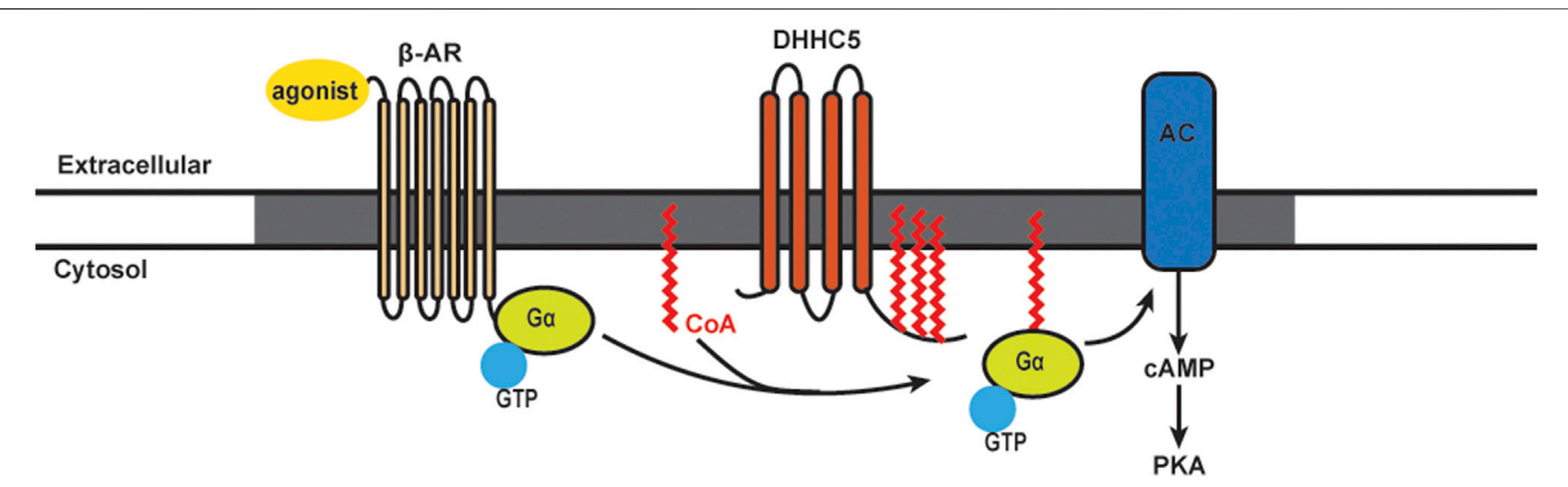

FIGURE 2 | Schematics of S-acylation of Ga protein and $\beta$-AR signaling pathway. Upon agonist stimulation, $\beta$-adrenergic receptors ( $\beta$-AR) bind DHHC5 palmitoylated $\mathrm{G} \alpha$ and leads to the activation of adenylyl cyclase (AC) and production of cAMP, followed by activation of Protein Kinase A (PKA). $\beta$-AR, AC and certain PKA subunits are enriched in caveolae (grey).

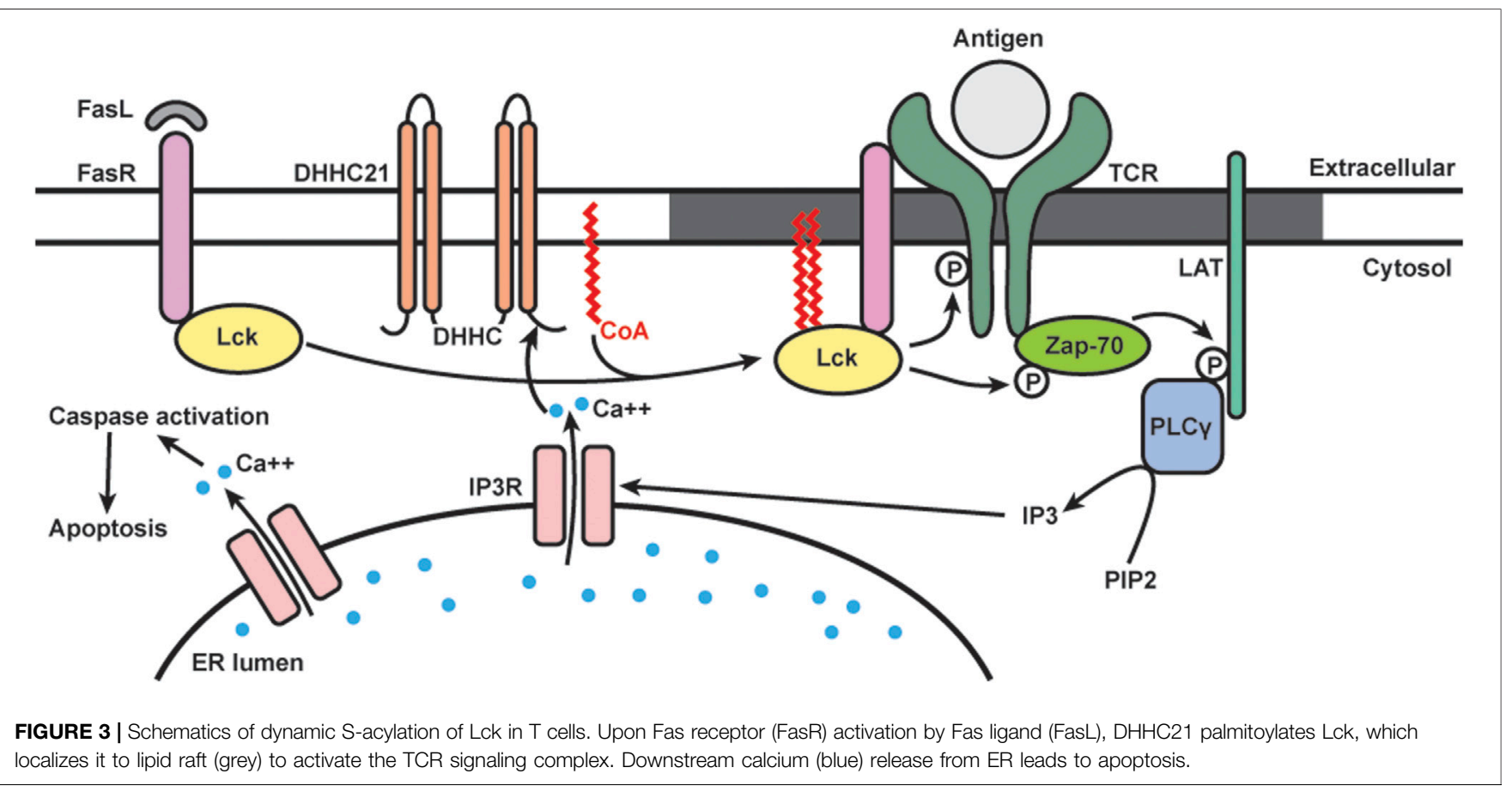

for cAMP production and downstream contractile responses in cultures cardiomyocytes (Chen et al., 2020).

In addition to in vitro models, the functional significance of DHHC5 in regulating cardiac function has been investigated in a DHHC5 gene trap mouse model (Li et al., 2012; Lin et al., 2013). Ischemia/reperfusion activates massive endocytosis (also called MEND) in cardiomyocytes. DHHC5 deficiency significantly reduces MEND upon reoxygenation, which improves cardiac performance. The substrates by which DHHC5 promotes MEND and sarcolemmal turnover are proposed to be the $\mathrm{Na} / \mathrm{K}$ pump, the Na pump regulator phospholemman, flotillin-2, and other myocyte membrane proteins (Lin et al., 2013). It was concluded that DHHC5 regulates contractility by modulating sarcolemmal turnover, and this process is detrimental during anoxic stress. It would be interesting in future studies to compare cardiac function in vivo in wild-type and gene trap DHHC5 mice under normal and cardiac stress conditions.

\section{Lck and T Cell Signaling}

The Fas receptor (FasR) is a member of the tumor necrosis factor receptor family, and upon activation by Fas ligand, it triggers apoptotic cell death (Nagata, 1997). In T cells, repeated T-cell receptor (TCR) stimulation and the binding of Fas ligand to the receptor leads to activation-induced cell death, a process crucial for the removal of reactive $\mathrm{T}$ cells after the invading antigens are eliminated (Green et al., 2003). Fas signaling in T cells involves 
multiple members of the canonical TCR signaling complex (Akimzhanov et al., 2010). Upon activation, Src kinases Lck and Fyn are recruited and phosphorylate the cytoplasmic tail of TCR, which subsequently recruits zeta chain-associated protein $70 \mathrm{kDa}$ (ZAP-70). ZAP-70 phosphorylates the adaptor protein linker for the activation of T cells (LAT). Activated LAT recruits a series of signaling proteins including phospholipase C- $\gamma 1$ (PLC $\gamma 1)$, which hydrolyzes phosphatidylinositol bisphosphate [Figure 3, reviewed in Huse (2009)]. Our group found that activation of Lck and TCR signaling is required for the production of secondary messenger inositol 1,4,5-triphosphate $\left(\mathrm{IP}_{3}\right)$ during Fas-mediated apoptosis in $\mathrm{T}$ cells (Akimzhanov et al., 2010).

Many members of the TCR signaling pathway are known S-acylated proteins. Lck is dually palmitoylated at Cys-3 and 5, and mutation of these sites prevents Lck from activating downstream TCR signaling (Paige et al., 1993; Yurchak and Sefton, 1995; Kabouridis et al., 1997). Our group is interested in studying Lck S-acylation and its functional roles in Fas signaling (Figure 3). We found that in T cells, S-acylation of both cysteines on Lck is required for Fas-mediated apoptotic events, including calcium release, caspase-3 activation, and cell death (Akimzhanov and Boehning, 2015). By using metabolic labeling, we analyzed the palmitic turnover kinetics on Lck and Fyn. We found that Lck has faster turnover rate (in minutes) than Fyn (in hours), suggesting that they are likely regulated by different enzymatic mechanisms despite very high homology in both structure and function. Notably, Lck has increased de novo palmitoylation within 2 min of Fas ligand stimulation, and the rate of palmitoylation decreased after $10 \mathrm{~min}$. This rapid and transient Lck palmitoylation kinetically correlates to activation of downstream events, including ZAP-70 and PLC $\gamma 1$ activation.

To study the enzymatic machineries regulating the rapid, stimulus-dependent Lck palmitoylation, we focused on plasma membrane localized DHHC enzymes. We identified DHHC21 as the enzyme responsible for rapid Lck palmitoylation and downstream Fas signaling in $\mathrm{T}$ cells. We also found that the rapid palmitoylation of Lck following Fas stimulation is dependent on intracellular calcium levels. This is likely mediated by a calcium/calmodulin binding site in the C-terminal tail of DHHC21 (Shayahati et al., 2020). Interestingly, we found that though APT1 deacylates Lck under resting conditions, it does not affect stimulus-dependent deacylation following Fas stimulation.

Multiple proteins in the Fas signaling pathways are known to require S-acylation for proper localization and downstream signaling. Fas receptor is palmitoylated by DHHC7 and recruited to lipid rafts to form stable oligomers important for the formation of the death-induced signaling complex (Chakrabandhu et al., 2007; Rossin et al., 2015). Both Lck and LAT palmitoylation lead to increased lipid raft affinity and ensure activation of TCR signaling cascade (Kabouridis et al., 1997; Zhang et al., 1998; Lin et al., 1999). However, most of these studies utilized cysteine mutant proteins and thus cannot reflect the dynamic acylation/deacylation cycles happening at the plasma membrane. Our study supports the well-known model in which lipid rafts serve as platforms for the assembly of TCR signaling proteins (Janes et al., 2000; Kabouridis, 2006; He and Marguet, 2008). Specifically, our study showed that the rapid, agonist-induced acylation and deacylation kinetics is temporally consistent with proximal signaling events. It is also worth noting that DHHC and APT proteins are identified as new classes of regulators of T-cell signaling. More recently, we have shown that DHHC21 is a critical regulator of $\mathrm{T}$ cell development/ differentiation in vivo using the depilated mouse model (Lin et al., 2013).

\section{N and H Ras Signaling}

The Ras family are small GTPases involved in cell signaling, proliferation, differentiation, and survival (Hancock, 2003; Castellano and Santos, 2011). In humans there are four Ras proteins: N-Ras, H-Ras, and two K-Ras variants (Hancock, 2003; Castellano and Santos, 2011; Cox et al., 2014; Hobbs et al., 2016). Traditionally, Ras was considered only to be active on the plasma membrane (Apolloni et al., 2000). Stimuli such as Son of Sevenless (SOS) or epidermal growth factor (EGF) activates Ras via the exchange of GDP for GTP on the protein (Bandaru et al., 2019). Subsequently, Ras-GTP recruits the serine/ threonine kinase Raf- 1 to the plasma membrane (Stokoe et al., 1994). Active Raf-1 then activates mitogen-activated protein kinase (MAPK), which phosphorylates and activates downstream substrates (Mor and Philips, 2006). Besides Raf-1 and its homologs, the best-studied effector of Ras is phosphatidylinositol 3-kinase (PI3K) (Mor and Philips, 2006). PI3K activates Akt and c-Jun N-terminal kinases (JNK) to promotes cell survival (Mor and Philips, 2006).

S-acylation is known to stabilize N-Ras and H-Ras at the plasma membrane (Figure 4) (Laude and Prior, 2008). S-acylation deficient N-Ras can still bind GTP, but cannot localize to the plasma membrane and loses the ability to activate both MAPK and PI3K downstream signaling pathways involved in cellular transformation (Cuiffo and Ren, 2010). Stimulation of growth factor receptors normally induces a rapid but transient activation of $\mathrm{H}$-Ras at the plasma membrane and delayed but long-lasting activity at the Golgi (Chiu et al., 2002; Rocks et al., 2005). Deacylation inhibitors have no effect on this EGF-induced transient increase of H-RasGTP on the plasma membrane, but they decrease the H-RasGTP pool on the Golgi. The activity of H-Ras on the Golgi also depends largely on retrograde transport of the activated protein from plasma membrane through the S-acylation cycle (Rocks et al., 2005).

In addition to the plasma membrane and Golgi, Ras is also activated on ER membranes (Chiu et al., 2002). In order to study how Ras localization regulates cell growth, S-acylation deficient H-Ras was specifically targeted to the Golgi, ER and plasma membrane. Ras located at the Golgi complex was the least efficient at activating Akt, while ER and Golgi were the preferred sites by Ras to activate JNK (Matallanas et al., 2006). The Ras pools present at plasma membrane were considerably less effective for activating Akt or JNK, but efficiently activated Erk. Ras localized to the Golgi induced slow growth of fibroblasts, while Ras localized in plasma membrane induced cell transformation (Matallanas et al., 2006). Thus, S-acylation 


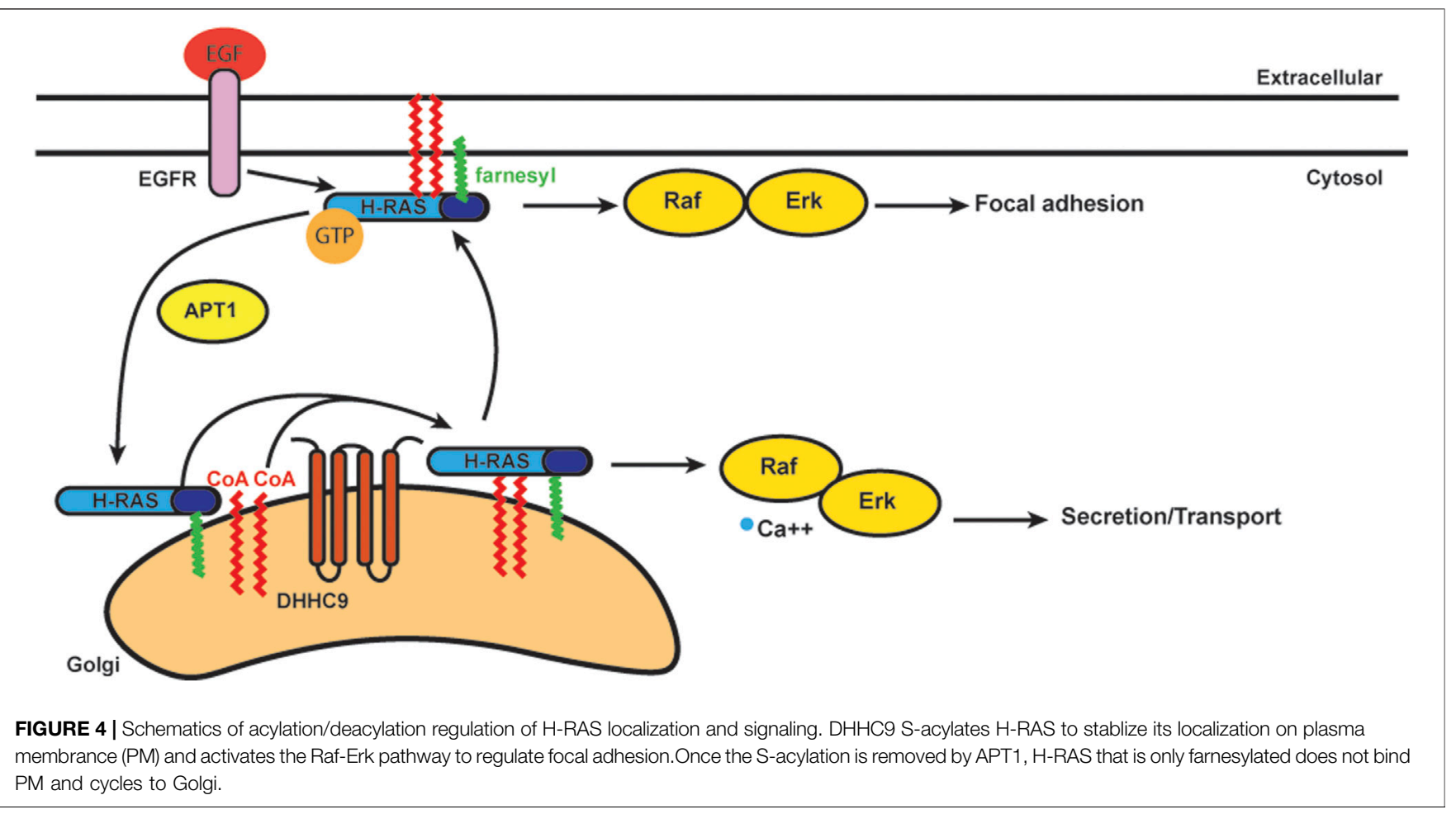

plays an important role in Ras localization and trafficking with implications for signaling and cell transformation.

As mentioned, trafficking of Ras from the Golgi to the plasma membrane requires S-acylation and proceeds via vesicular transport (Choy et al., 1999; Apolloni et al., 2000). N-Ras and $\mathrm{H}$-Ras are S-acylated at one (N-Ras) or two (H-Ras) cysteines by DHHC9-GPC16 at the Golgi apparatus and transported to the plasma membrane (Swarthout et al., 2005). Upon deacylation they transport back to the Golgi to complete the Golgi/plasma membrane transport cycle (Lin et al., 2017). Blocking deacylation prolongs plasma membrane association of Ras and dysregulates the endomembrane system (Dekker et al., 2010; Rocks et al., 2010). APT1 was identified for its in vitro deacylation of $H$-Ras (Duncan and Gilman, 1998). ABHD17, as mentioned above, can deacylate N-Ras (Lin and Conibear, 2015). Palmitate turnover of $\mathrm{N}$-Ras was significantly inhibited when all three ABHD17 members were downregulated simultaneously. The number of $\mathrm{S}$-acylation sites can also affect the half-life of N-Ras and H-Ras on the plasma membrane. N-Ras has only one S-acylation site, and its half-life is much shorter than H-Ras, which has two S-acylation sites (Rocks et al., 2005).

\section{CONCLUSION}

In this review, we summarized key findings in the field of protein S-acylation and the enzymatic regulators. Much of the field is now focusing on dynamic acylation/deacylation cycles and the role of this process in cell signaling. A significant gap in our understanding is how DHHC protein acyltransferases and acyl-protein thioesterases are regulated in a stimulus-dependent manner. This will be essential for understanding how they regulate cell signaling and the potential for therapeutic intervention. Another major question is the mechanisms by which DHHC and APT/ABHD proteins determine substrate specificity. Despite the advent of large-scale unbiased peptide substrate screens and high resolution structures, this is still a poorly understood aspect of the acylation machinery.

A number of pharmacological tools have been developed to mediate S-acylation reactions. The most widely used inhibitor of $\mathrm{S}$-acylation is 2-bromopalmitate (2BP), a non-metabolizable analogue of palmitate (Webb et al., 2000). 2BP and other lipid-based compounds such as tunicamycin (Patterson and Skene, 1995) and cerulenin (DeJesus and Bizzozero, 2002) non-selectively inhibits the incorporation of fatty acyl groups onto target proteins. However, they are known to be highly toxic to cultured cells and target many proteins in the cellular lipid metabolism pathways, making them poor tools to study S-acylation (reviewed in Draper and Smith (2009), Chavda et al. (2014)]. Given the increasing interest in targeting protein $\mathrm{S}$-acylation in various diseases, several chemical screens have been conducted to identify better inhibitors of DHHC enzymes or specific S-acylation substrates (Ducker et al., 2006; Hamel et al., 2016; Ganesan et al., 2017). Further studies are needed to define the mechanisms of actions for the compounds identified in these screens. In the future we anticipate the development of novel chemical tools with specific utility in studying highly dynamic and transient acylation/deacylation cycles. As an example, a new methodology for site-specific incorporation of lipids at cycloalkyne-conjugated unnatural amino acids was recently described which should facilitate understanding the attachment of specific lipids at defined sites "on demand" (Li et al., 2020). 
We have a nascent understanding of the functional outcomes of the attachment of lipids other than the 16-carbon saturated fatty acid palmitic acid. Future work will need to address the functional outcomes and prevalence of S-acylation with other chain lengths or unsaturated fatty acids. As an example, S-acylation with unsaturated lipids such as arachidonic acid would be predicted to exclude substrates from rafts, which could be an important regulatory mechanism for the inclusion or exclusion of S-acylated proteins from rafts. Finally, the field would benefit with more animal/in vivo models. The function of the broad diversity of protein acyltransferases and the ever expanding family of acyl-protein thioesterases is still very poorly understood in vivo.

\section{REFERENCES}

Abrami, L., Dallavilla, T., Sandoz, P. A., Demir, M., Kunz, B., Savoglidis, G., et al. (2017). Identification and dynamics of the human ZDHHC16-ZDHHC6 palmitoylation cascade. Elife 6, 278. doi:10.7554/eLife.27826

Abrami, L., Kunz, B., Iacovache, I., and van der Goot, F. G. (2008). Palmitoylation and ubiquitination regulate exit of the Wnt signaling protein LRP6 from the endoplasmic reticulum. Proc. Natl. Acad. Sci. USA 105, 5384-5389. doi:10.1073/ pnas.0710389105

Abrami, L., Leppla, S. H., and van der Goot, F. G. (2006). Receptor palmitoylation and ubiquitination regulate anthrax toxin endocytosis. J. Cell Biol. 172, 309-320. doi:10.1083/jcb.200507067

Adachi, N., Hess, D. T., McLaughlin, P., and Stamler, J. S. (2016). S-palmitoylation of a novel site in the $\beta 2$-adrenergic receptor associated with a novel intracellular itinerary. J. Biol. Chem. 291, 20232-20246. doi:10.1074/jbc.M116.725762

Akimzhanov, A. M., and Boehning, D. (2015). Rapid and transient palmitoylation of the tyrosine kinase Lck mediates Fas signaling. Proc. Natl. Acad. Sci. USA 112, 11876-11880. doi:10.1073/pnas.1509929112

Akimzhanov, A. M., Wang, X., Sun, J., and Boehning, D. (2010). T-cell receptor complex is essential for Fas signal transduction. Proc. Natl. Acad. Sci. USA 107, 15105-15110. doi:10.1073/pnas.1005419107

Amara, N., Foe, I. T., Onguka, O., Garland, M., and Bogyo, M. (2019). Synthetic fluorogenic peptides reveal dynamic substrate specificity of depalmitoylases. Cell Chem. Biol. 26, e35-e37. doi:10.1016/j.chembiol.2018.10.005

Apolloni, A., Prior, I. A., Lindsay, M., Parton, R. G., and Hancock, J. F. (2000). $\mathrm{H}$-ras but not K-ras traffics to the plasma membrane through the exocytic pathway. Mol. Cell Biol. 20, 2475-2487. doi:10.1128/mcb.20.7.2475-2487.2000

Arni, S., Ilangumaran, S., van Echten-Deckert, G., Sandhoff, K., Poincelet, M., Briol, A., et al. (1996). Differential regulation of Src-family protein tyrosine kinases in GPI domains of T lymphocyte plasma membranes. Biochem. Biophys. Res. Commun. 225, 801-807. doi:10.1006/bbrc.1996.1254

Ashkenazi, A., and Dixit, V. M. (1998). Death receptors: signaling and modulation. Science 281, 1305-1308. doi:10.1126/science.281.5381.1305

Bachovchin, D. A., Ji, T., Li, W., Simon, G. M., Blankman, J. L., Adibekian, A., et al. (2010). Superfamily-wide portrait of serine hydrolase inhibition achieved by library-versus-library screening. Proc. Natl. Acad. Sci. USA 107, 20941-20946. doi:10.1073/pnas.1011663107

Baekkeskov, S., Aanstoot, H. J., Christgau, S., Reetz, A., Solimena, M., Cascalho, M., et al. (1990). Identification of the $64 \mathrm{~K}$ autoantigen in insulin-dependent diabetes as the GABA-synthesizing enzyme glutamic acid decarboxylase. Nature 347, 151-156. doi:10.1038/347151a0

Baker, T. L., Zheng, H., Walker, J., Coloff, J. L., and Buss, J. E. (2003). Distinct rates of palmitate turnover on membrane-bound cellular and oncogenic H-ras. J. Biol. Chem. 278, 19292-19300. doi:10.1074/jbc.M206956200

Balijepalli, R. C., and Kamp, T. J. (2008). Caveolae, ion channels and cardiac arrhythmias. Prog. Biophys. Mol. Biol. 98, 149-160. doi:10.1016/j.pbiomolbio. 2009.01.012

Bandaru, P., Kondo, Y., and Kuriyan, J. (2019). The interdependent activation of son-of-sevenless and ras. Cold Spring Harb Perspect. Med. 9, 315. doi:10.1101/ cshperspect.a031534

\section{AUTHOR CONTRIBUTIONS}

All authors contribute to the writing of this manuscript. JC and FY wrote the first draft. JC, FY, and DB edited the draft. JC and FY prepared the figures and tables. JC and DB finalized the manuscript.

\section{FUNDING}

This work was supported by grants GM081685 and GM130840 from the National Institutes of Health and startup funds provided by Cooper Medical School of Rowan University (DB).

Bartels, D. J., Mitchell, D. A., Dong, X., and Deschenes, R. J. (1999). Erf2, a novel gene product that affects the localization and palmitoylation of Ras 2 in Saccharomyces cerevisiae. Mol. Cell Biol. 19, 6775-6787. doi:10.1128/mcb.19. 10.6775

Bhatnagar, R. S., and Gordon, J. I. (1997). Understanding covalent modifications of proteins by lipids: where cell biology and biophysics mingle. Trends Cell Biol. 7, 14-20. doi:10.1016/S0962-8924(97)10044-7

Bizzozero, O. A. (1995). Chemical analysis of acylation sites and species. Method Enzymol. 250, 361-379. doi:10.1016/0076-6879(95)50085-5

Blanc, M., David, F. P. A., and van der Goot, F. G. (2019). SwissPalm 2: protein S-palmitoylation database. Methods Mol. Biol. 2009, 203-214. doi:10.1007/9781-4939-9532-5_16

Blanc, M., David, F., Abrami, L., Migliozzi, D., Armand, F., Bürgi, J., et al. (2015). SwissPalm: protein palmitoylation database. SwissPalm: Protein Palmitoylation databaseF1000Res 4, 261. doi:10.12688/f1000research.6464.1

Brett, K., Kordyukova, L. V., Serebryakova, M. V., Mintaev, R. R., Alexeevski, A. V., and Veit, M. (2014). Site-specific S-acylation of influenza virus hemagglutinin: the location of the acylation site relative to the membrane border is the decisive factor for attachment of stearate. J. Biol. Chem. 289, 34978-34989. doi:10.1074/ jbc.M114.586180

Brigidi, G. S., and Bamji, S. X. (2013). Detection of protein palmitoylation in cultured hippocampal neurons by immunoprecipitation and acyl-biotin exchange (ABE). J. Vis. Exp. 18(72), 50031 doi:10.3791/50031

Brigidi, G. S., Santyr, B., Shimell, J., Jovellar, B., and Bamji, S. X. (2015). Activityregulated trafficking of the palmitoyl-acyl transferase DHHC5. Nat. Commun. 6, 8200. doi: $10.1038 /$ ncomms 9200

Buglino, J. A., and Resh, M. D. (2008). Hhat is a palmitoylacyltransferase with specificity for N-palmitoylation of Sonic Hedgehog. J. Biol. Chem. 283, 22076-22088. doi:10.1074/jbc.M803901200

Calero, G., Gupta, P., Nonato, M. C., Tandel, S., Biehl, E. R., Hofmann, S. L., et al. (2003). The crystal structure of palmitoyl protein thioesterase-2 (PPT2) reveals the basis for divergent substrate specificities of the two lysosomal thioesterases, PPT1 and PPT2. J. Biol. Chem. 278, 37957-37964. doi:10.1074/jbc.M301225200

Camp, L. A., and Hofmann, S. L. (1993). Purification and properties of a palmitoylprotein thioesterase that cleaves palmitate from H-Ras. J. Biol. Chem. 268, 22566-22574. doi:10.1016/s0021-9258(18)41567-0

Camp, L. A., Verkruyse, L. A., Afendis, S. J., Slaughter, C. A., and Hofmann, S. L. (1994). Molecular cloning and expression of palmitoyl-protein thioesterase. J. Biol. Chem. 269, 23212-23219. doi:10.1016/s0021-9258(17)31641-1

Cao, Y., Qiu, T., Kathayat, R. S., Azizi, S. A., Thorne, A. K., Ahn, D., et al. (2019). ABHD10 is an S-depalmitoylase affecting redox homeostasis through peroxiredoxin-5. Nat. Chem. Biol. 15, 1232-1240. doi:10.1038/s41589-0190399-y

Caron, J. M. (1997). Posttranslational modification of tubulin by palmitoylation: I. In vivo and cell-free studies. Mol. Biol. Cel 8, 621-636. doi: $10.1091 / \mathrm{mbc} .8 .4 .621$

Carr, S. A., Biemann, K., Shoji, S., Parmelee, D. C., and Titani, K. (1982) $\mathrm{n}$-Tetradecanoyl is the NH2-terminal blocking group of the catalytic subunit of cyclic AMP-dependent protein kinase from bovine cardiac muscle. Proc. Natl. Acad. Sci. USA 79, 6128-6131. doi:10.1073/pnas.79.20.6128 
Castellano, E., and Santos, E. (2011). Functional specificity of ras isoforms: so similar but so different. Genes Cancer 2, 216-231. doi:10.1177/ 1947601911408081

Chai, S., Cambronne, X. A., Eichhorn, S. W., and Goodman, R. H. (2013). MicroRNA-134 activity in somatostatin interneurons regulates H-Ras localization by repressing the palmitoylation enzyme, DHHC9. Proc. Natl. Acad. Sci. USA 110, 17898-17903. doi:10.1073/pnas.1317528110

Chakrabandhu, K., Hérincs, Z., Huault, S., Dost, B., Peng, L., Conchonaud, F., et al. (2007). Palmitoylation is required for efficient Fas cell death signaling. EMBO J. 26, 209-220. doi:10.1038/sj.emboj.7601456

Chamberlain, L. H., and Shipston, M. J. (2015). The physiology of protein S-acylation. Physiol. Rev. 95, 341-376. doi:10.1152/physrev.00032.2014

Charollais, J., and Van Der Goot, F. G. (2009). Palmitoylation of membrane proteins (Review). Mol. Membr. Biol. 26, 55-66. doi:10.1080/ 09687680802620369

Chavda, B., Arnott, J. A., and Planey, S. L. (2014). Targeting protein palmitoylation: selective inhibitors and implications in disease. Expert Opin. Drug Discov. 9, 1005-1019. doi:10.1517/17460441.2014.933802

Chen, B., Sun, Y., Niu, J., Jarugumilli, G. K., and Wu, X. (2018). Protein lipidation in cell signaling and diseases: function, regulation, and therapeutic opportunities. Cell Chem. Biol. 25, 817-831. doi:10.1016/j.chembiol.2018. 05.003

Chen, J. J., and Boehning, D. (2017). Protein lipidation as a regulator of apoptotic calcium release: relevance to cancer. Front. Oncol. 7, 138. doi:10.3389/fonc. 2017.00138

Chen, J. J., Marsden, A. N., Scott, C. A., Akimzhanov, A. M., and Boehning, D. (2019). DHHC5 mediates beta-adrenergic signaling in cardiomyocytes by targeting galpha proteins. Biophys. J. 118 (4), 826-835. doi:10.1016/j.bpj. 2019.08.018

Chen, J. J., Marsden, A. N., Scott, C. A., Akimzhanov, A. M., and Boehning, D. (2020). DHHC5 mediates $\beta$-adrenergic signaling in cardiomyocytes by targeting Ga proteins. Biophys. J. 118, 826-835. doi:10.1016/j.bpj.2019.08.018

Chiu, V. K., Bivona, T., Hach, A., Sajous, J. B., Silletti, J., Wiener, H., et al. (2002). Ras signalling on the endoplasmic reticulum and the Golgi. Nat. Cel Biol. 4, 343-350. doi:10.1038/ncb783

Choy, E., Chiu, V. K., Silletti, J., Feoktistov, M., Morimoto, T., Michaelson, D., et al. (1999). Endomembrane trafficking of ras: the CAAX motif targets proteins to the ER and Golgi. Cell 98, 69-80. doi:10.1016/S0092-8674(00)80607-8

Clapham, D. E., and Neer, E. J. (1993). New roles for G-protein beta gamma-dimers in transmembrane signalling. Nature 365, 403-406. doi:10.1038/365403a0

Clark, D. J., Fondrie, W. E., Yang, A., and Mao, L. (2016). Triple SILAC quantitative proteomic analysis reveals differential abundance of cell signaling proteins between normal and lung cancer-derived exosomes. J. Proteomics 133, 161-169. doi:10.1016/j.jprot.2015.12.023

Collins, M. O., Woodley, K. T., and Choudhary, J. S. (2017). Global, site-specific analysis of neuronal protein S-acylation. Sci. Rep. 7, 4683. doi:10.1038/s41598017-04580-1

Colquhoun, D. R., Lyashkov, A. E., Ubaida Mohien, C., Aquino, V. N., Bullock, B. T., Dinglasan, R. R., et al. (2015). Bioorthogonal mimetics of palmitoyl-CoA and myristoyl-CoA and their subsequent isolation by click chemistry and characterization by mass spectrometry reveal novel acylated host-proteins modified by HIV-1 infection. Proteomics 15, 2066-2077. doi:10.1002/pmic. 201500063

Cox, A. D., Fesik, S. W., Kimmelman, A. C., Luo, J., and Der, C. J. (2014). Drugging the undruggable RAS: mission possible?. Nat. Rev. Drug Discov. 13, 828-851. doi:10.1038/nrd4389

Cuiffo, B., and Ren, R. (2010). Palmitoylation of oncogenic NRAS is essential for leukemogenesis. Blood 115, 3598-3605. doi:10.1182/blood-2009-03-213876

David, V., Hochstenbach, F., Rajagopalan, S., and Brenner, M. B. (1993). Interaction with newly synthesized and retained proteins in the endoplasmic reticulum suggests a chaperone function for human integral membrane protein IP90 (calnexin). J. Biol. Chem. 268, 9585-9592. doi:10.1016/s0021-9258(18) 98391-2

Degtyarev, M. Y., Spiegel, A. M., and Jones, T. L. (1994). Palmitoylation of a G protein alpha i subunit requires membrane localization not myristoylation. J. Biol. Chem. 269, 30898-30903. doi:10.1016/s0021-9258(18)47366-8
Degtyarev, M. Y., Spiegel, A. M., and Jones, T. L. (1993). The G protein alpha s subunit incorporates $[3 \mathrm{H}]$ palmitic acid and mutation of cysteine- 3 prevents this modification. Biochemistry 32, 8057-8061. doi:10.1021/bi00083a001

DeJesus, G., and Bizzozero, O. A. (2002). Effect of 2-fluoropalmitate, cerulenin and tunicamycin on the palmitoylation and intracellular translocation of myelin proteolipid protein. Neurochem. Res. 27, 1669-1675. doi:10.1023/a: 1021643229028

Dekker, F. J., Rocks, O., Vartak, N., Menninger, S., Hedberg, C., Balamurugan, R., et al. (2010). Small-molecule inhibition of APT1 affects Ras localization and signaling. Nat. Chem. Biol. 6, 449-456. doi:10.1038/nchembio.362

DeMar, J. C., Jr., and Anderson, R. E. (1997). Identification and quantitation of the fatty acids composing the CoA ester pool of bovine retina, heart, and liver. J. Biol. Chem. 272, 31362-31368. doi:10.1074/jbc.272.50.31362

Devaraj, N. K. (2018). The future of bioorthogonal chemistry. ACS Cent. Sci. 4, 952-959. doi:10.1021/acscentsci.8b00251

Devedjiev, Y., Dauter, Z., Kuznetsov, S. R., Jones, T. L., and Derewenda, Z. S. (2000). Crystal structure of the human acyl protein thioesterase I from a single X-ray data set to 1.5 A. Structure 8, 1137-1146. doi:10.1016/s0969-2126(00) 00529-3

Diaz-Rohrer, B., Levental, K. R., and Levental, I. (2014). Rafting through traffic: membrane domains in cellular logistics. Biochim. Biophys. Acta 1838, 3003-3013. doi:10.1016/j.bbamem.2014.07.029

Dietzen, D. J., Hastings, W. R., and Lublin, D. M. (1995). Caveolin is palmitoylated on multiple cysteine residues. Palmitoylation is not necessary for localization of caveolin to caveolae. J. Biol. Chem. 270, 6838-6842. doi:10.1074/jbc.270.12.6838

Draper, J. M., and Smith, C. D. (2009). Palmitoyl acyltransferase assays and inhibitors (Review). Mol. Membr. Biol. 26, 5-13. doi:10.1080/ 09687680802683839

Drisdel, R. C., Alexander, J. K., Sayeed, A., and Green, W. N. (2006). Assays of protein palmitoylation. Methods 40, 127-134. doi:10.1016/j.ymeth.2006.04.015

Drisdel, R. C., and Green, W. N. (2004). Labeling and quantifying sites of protein palmitoylation. Biotechniques 36, 276-285. doi:10.2144/04362RR02

Du, K., Murakami, S., Sun, Y., Kilpatrick, C. L., and Luscher, B. (2017). DHHC7 palmitoylates glucose transporter 4 (Glut4) and regulates Glut4 membrane translocation. J. Biol. Chem. 292, 2979-2991. doi:10.1074/jbc.M116.747139

Ducker, C. E., Draper, J. M., Xia, Z., and Smith, C. D. (2006a). In vitro and cellular assays for palmitoyl acyltransferases using fluorescent lipidated peptides. Methods 40, 166-170. doi:10.1016/j.ymeth.2006.06.019

Ducker, C. E., Griffel, L. K., Smith, R. A., Keller, S. N., Zhuang, Y., Xia, Z., et al. (2006b). Discovery and characterization of inhibitors of human palmitoyl acyltransferases. Mol. Cancer Ther. 5, 1647-1659. doi:10.1158/1535-7163. MCT-06-0114

Duncan, J. A., and Gilman, A. G. (1998). A cytoplasmic acyl-protein thioesterase that removes palmitate from $\mathrm{G}$ protein alpha subunits and p21(RAS). J. Biol. Chem. 273, 15830-15837. doi:10.1074/jbc.273.25.15830

Dzimiri, N. (1999). Regulation of beta-adrenoceptor signaling in cardiac function and disease. Pharmacol. Rev. 51, 465-501.

Edmonds, M. J., Geary, B., Doherty, M. K., and Morgan, A. (2017). Analysis of the brain palmitoyl-proteome using both acyl-biotin exchange and acyl-resinassisted capture methods. Sci. Rep. 7, 3299. doi:10.1038/s41598-017-03562-7

Ernst, A. M., Syed, S. A., Zaki, O., Bottanelli, F., Zheng, H., Hacke, M., et al. (2018). S-palmitoylation sorts membrane cargo for anterograde transport in the Golgi. Dev. Cell 47, 479-e7. doi:10.1016/j.devcel.2018.10.024

Essandoh, K., Philippe, J. M., Jenkins, P. M., and Brody, M. J. (2020). Palmitoylation: a fatty regulator of myocardial electrophysiology. Front. Physiol. 11, 108. doi:10.3389/fphys.2020.00108

Feig, C., Tchikov, V., Schütze, S., and Peter, M. E. (2007). Palmitoylation of CD95 facilitates formation of SDS-stable receptor aggregates that initiate apoptosis signaling. EMBO J. 26, 221-231. doi:10.1038/sj.emboj.7601460

Feldman, M., and van der Goot, F. G. (2009). Novel ubiquitin-dependent quality control in the endoplasmic reticulum. Trends Cell Biol. 19, 357-363. doi:10. 1016/j.tcb.2009.05.005

Fernández-Hernando, C., Fukata, M., Bernatchez, P. N., Fukata, Y., Lin, M. I., Bredt, D. S., et al. (2006). Identification of Golgi-localized acyl transferases that palmitoylate and regulate endothelial nitric oxide synthase. J. Cel Biol. 174, 369-377. doi:10.1083/jcb.200601051 
Forrester, M. T., Hess, D. T., Thompson, J. W., Hultman, R., Moseley, M. A., Stamler, J. S., et al. (2011). Site-specific analysis of protein S-acylation by resinassisted capture. J. Lipid Res. 52, 393-398. doi:10.1194/jlr.D011106

Fukata, Y., Iwanaga, T., and Fukata, M. (2006). Systematic screening for palmitoyl transferase activity of the DHHC protein family in mammalian cells. Methods 40, 177-182. doi:10.1016/j.ymeth.2006.05.015

Fukata, Y., Murakami, T., Yokoi, N., and Fukata, M. (2016). Local palmitoylation cycles and specialized membrane domain organization. Curr. Top. Membr. 77, 97-141. doi:10.1016/bs.ctm.2015.10.003

Ganesan, L., Shieh, P., Bertozzi, C. R., and Levental, I. (2017). Click-chemistry based high throughput screening platform for modulators of ras palmitoylation. Sci. Rep. 7, 41147. doi:10.1038/srep41147

Gao, X., and Hannoush, R. N. (2014a). Method for cellular imaging of palmitoylated proteins with clickable probes and proximity ligation applied to Hedgehog, tubulin, and Ras. J. Am. Chem. Soc. 136, 4544-4550. doi:10.1021/ ja410068g

Gao, X., and Hannoush, R. N. (2014b). Single-cell in situ imaging of palmitoylation in fatty-acylated proteins. Nat. Protoc. 9, 2607-2623. doi:10.1038/nprot. 2014.179

Gök, C., Plain, F., Robertson, A. D., Howie, J., Baillie, G. S., Fraser, N. J., et al. (2020). Dynamic palmitoylation of the sodium-calcium exchanger modulates its structure, affinity for lipid-ordered domains, and inhibition by XIP. Cell Rep. 31, 107697. doi:10.1016/j.celrep.2020.107697

González Montoro, A., Chumpen Ramirez, S., and Valdez Taubas, J. (2015). The canonical DHHC motif is not absolutely required for the activity of the yeast S-acyltransferases Swfl and Pfa4. J. Biol. Chem. 290, 22448-22459. doi:10.1074/ jbc.M115.651356

Gonzalo, S., Greentree, W. K., and Linder, M. E. (1999). SNAP-25 is targeted to the plasma membrane through a novel membrane-binding domain. J. Biol. Chem. 274, 21313-21318. doi:10.1074/jbc.274.30.21313

Gorleku, O. A., Barns, A. M., Prescott, G. R., Greaves, J., and Chamberlain, L. H. (2011). Endoplasmic reticulum localization of DHHC palmitoyltransferases mediated by lysine-based sorting signals. J. Biol. Chem. 286, 39573-39584. doi:10.1074/jbc.M111.272369

Gratton, J. P., Bernatchez, P., and Sessa, W. C. (2004). Caveolae and caveolins in the cardiovascular system. Circ. Res. 94, 1408-1417. doi:10.1161/01.RES. 0000129178.56294 .17

Greaves, J., and Chamberlain, L. H. (2011). Differential palmitoylation regulates intracellular patterning of SNAP25. J. Cell Sci. 124, 1351-1360. doi:10.1242/jcs. 079095

Greaves, J., Gorleku, O. A., Salaun, C., and Chamberlain, L. H. (2010). Palmitoylation of the SNAP25 protein family: specificity and regulation by DHHC palmitoyl transferases. J. Biol. Chem. 285, 24629-24638. doi:10.1074/ jbc.M110.119289

Greaves, J., Munro, K. R., Davidson, S. C., Riviere, M., Wojno, J., Smith, T. K., et al. (2017). Molecular basis of fatty acid selectivity in the zDHHC family of S-acyltransferases revealed by click chemistry. Proc. Natl. Acad. Sci. USA 114, E1365-E1374. doi:10.1073/pnas.1612254114

Green, D. R., Droin, N., and Pinkoski, M. (2003). Activation-induced cell death in T cells. Immunol. Rev. 193, 70-81. doi:10.1034/j.1600-065x.2003.00051.x

Hamel, L. D., Lenhart, B. J., Mitchell, D. A., Santos, R. G., Giulianotti, M. A., and Deschenes, R. J. (2016). Identification of protein palmitoylation inhibitors from a scaffold ranking library. Comb. Chem. High Throughput Screen. 19, 262-274. doi:10.2174/1386207319666160324123844

Hancock, J. F., Magee, A. I., Childs, J. E., and Marshall, C. J. (1989). All ras proteins are polyisoprenylated but only some are palmitoylated. Cell 57, 1167-1177. doi:10.1016/0092-8674(89)90054-8

Hancock, J. F. (2003). Ras proteins: different signals from different locations. Nat. Rev. Mol. Cel Biol. 4, 373-384. doi:10.1038/nrm1105

Hannoush, R. N., and Sun, J. (2010). The chemical toolbox for monitoring protein fatty acylation and prenylation. Nat. Chem. Biol. 6, 498-506. doi:10.1038/ nchembio. 388

Harder, T., and Kuhn, M. (2000). Selective accumulation of raft-associated membrane protein LAT in T cell receptor signaling assemblies. J. Cell Biol. 151, 199-208. doi:10.1083/jcb.151.2.199

Hayashi, T., Rumbaugh, G., and Huganir, R. L. (2005). Differential regulation of AMPA receptor subunit trafficking by palmitoylation of two distinct sites. Neuron 47, 709-723. doi:10.1016/j.neuron.2005.06.035
Hayashi, T., Thomas, G. M., and Huganir, R. L. (2009). Dual palmitoylation of NR2 subunits regulates NMDA receptor trafficking. Neuron 64, 213-226. doi:10. 1016/j.neuron.2009.08.017

He, H. T., and Marguet, D. (2008). T-cell antigen receptor triggering and lipid rafts: a matter of space and time scales. Talking Point on the involvement of lipid rafts in T-cell activation. EMBO Rep. 9, 525-530. doi:10.1038/embor.2008.78

Hering, H., Lin, C. C., and Sheng, M. (2003). Lipid rafts in the maintenance of synapses, dendritic spines, and surface AMPA receptor stability. J. Neurosci. 23, 3262-3271. doi:10.1523/jneurosci.23-08-03262.2003

Hobbs, G. A., Der, C. J., and Rossman, K. L. (2016). RAS isoforms and mutations in cancer at a glance. J. Cell Sci. 129, 1287-1292. doi:10.1242/jcs.182873

Howie, J., Reilly, L., Fraser, N. J., Vlachaki Walker, J. M., Wypijewski, K. J., Ashford, M. L., et al. (2014). Substrate recognition by the cell surface palmitoyl transferase DHHC5. Proc. Natl. Acad. Sci. USA 111, 17534-17539. doi:10. 1073/pnas.1413627111

Hsieh, J. C., Lee, L., Zhang, L., Wefer, S., Brown, K., DeRossi, C., et al. (2003). Mesd encodes an LRP5/6 chaperone essential for specification of mouse embryonic polarity. Cell 112, 355-367. doi:10.1016/s0092-8674(03)00045-x

Huang, K., Sanders, S., Singaraja, R., Orban, P., Cijsouw, T., Arstikaitis, P., et al. (2009). Neuronal palmitoyl acyl transferases exhibit distinct substrate specificity. FASEB J. 23, 2605-2615. doi:10.1096/fj.08-127399

Huang, K., Yanai, A., Kang, R., Arstikaitis, P., Singaraja, R. R., Metzler, M., et al. (2004). Huntingtin-interacting protein HIP14 is a palmitoyl transferase involved in palmitoylation and trafficking of multiple neuronal proteins. Neuron 44, 977-986. doi:10.1016/j.neuron.2004.11.027

Huse, M. (2009). The T-cell-receptor signaling network. J. Cell Sci. 122, 1269-1273. doi: $10.1242 /$ jcs. 042762

Jackson, J. H., Cochrane, C. G., Bourne, J. R., Solski, P. A., Buss, J. E., and Der, C. J. (1990). Farnesol modification of Kirsten-ras exon 4B protein is essential for transformation. Proc. Natl. Acad. Sci. USA 87, 3042-3046. doi:10.1073/pnas.87. 8.3042

Jahn, R., and Scheller, R. H. (2006). SNAREs--engines for membrane fusion. Nat. Rev. Mol. Cell Biol. 7, 631-643. doi:10.1038/nrm2002

Janes, P. W., Ley, S. C., Magee, A. I., and Kabouridis, P. S. (2000). The role of lipid rafts in T cell antigen receptor (TCR) signalling. Semin. Immunol. 12, 23-34. doi:10.1006/smim.2000.0204

Jennings, B. C., and Linder, M. E. (2012). DHHC protein S-acyltransferases use similar ping-pong kinetic mechanisms but display different acyl-CoA specificities. J. Biol. Chem. 287, 7236-7245. doi:10.1074/jbc.M111.337246

Jeyifous, O., Lin, E. I., Chen, X., Antinone, S. E., Mastro, R., Drisdel, R., et al. (2016). Palmitoylation regulates glutamate receptor distributions in postsynaptic densities through control of PSD95 conformation and orientation. Proc. Natl. Acad. Sci. USA 113, E8482-E8491. doi:10.1073/pnas.1612963113

Jiang, H., Zhang, X., Chen, X., Aramsangtienchai, P., Tong, Z., and Lin, H. (2018). Protein lipidation: occurrence, mechanisms, biological functions, and enabling technologies. Chem. Rev. 118, 919-988. doi:10.1021/acs.chemrev.6b00750

Jing, H., Zhang, X., Wisner, S. A., Chen, X., Spiegelman, N. A., Linder, M. E., et al. (2017). SIRT2 and lysine fatty acylation regulate the transforming activity of K-Ras4a. Elife 6. doi:10.7554/eLife.32436

Jones, M. L., Collins, M. O., Goulding, D., Choudhary, J. S., and Rayner, J. C. (2012). Analysis of protein palmitoylation reveals a pervasive role in Plasmodium development and pathogenesis. Cell Host Microbe 12, 246-258. doi:10.1016/j.chom.2012.06.005

Jones, T. L., Degtyarev, M. Y., and Backlund, P. S., Jr. (1997). The stoichiometry of $\mathrm{G}$ alpha(s) palmitoylation in its basal and activated states. Biochemistry 36, 7185-7191. doi:10.1021/bi9628376

Joseph, M., and Nagaraj, R. (1995). Interaction of peptides corresponding to fatty acylation sites in proteins with model membranes. J. Biol. Chem. 270, 16749-16755. doi:10.1074/jbc.270.28.16749

Kabouridis, P. S., Magee, A. I., and Ley, S. C. (1997). S-acylation of LCK protein tyrosine kinase is essential for its signalling function in T lymphocytes. EMBO J. 16, 4983-4998. doi:10.1093/emboj/16.16.4983

Kabouridis, P. S. (2006). Lipid rafts in T cell receptor signalling. Mol. Membr. Biol. 23, 49-57. doi:10.1080/09687860500453673

Kamiya, Y., Sakurai, A., Tamura, S., and Takahashi, N. (1978). Structure of rhodotorucine $\mathrm{A}$, a novel lipopeptide, inducing mating tube formation in Rhodosporidium toruloides. Biochem. Biophys. Res. Commun. 83, 1077-1083. doi:10.1016/0006-291x(78)91505-x 
Kanaani, J., Diacovo, M. J., El-Husseini, Ael-D., Bredt, D. S., and Baekkeskov, S. (2004). Palmitoylation controls trafficking of GAD65 from Golgi membranes to axon-specific endosomes and a Rab5a-dependent pathway to presynaptic clusters. J. Cell Sci. 117, 2001-2013. doi:10.1242/jcs.01030

Kanaani, J., el-Husseini, A.-D., Aguilera-Moreno, A., Diacovo, J. M., Bredt, D. S., and Baekkeskov, S. (2002). A combination of three distinct trafficking signals mediates axonal targeting and presynaptic clustering of GAD65. J. Cell Biol. 158, 1229-1238. doi:10.1083/jcb.200205053

Kanaani, J., Patterson, G., Schaufele, F., Lippincott-Schwartz, J., and Baekkeskov, S. (2008). A palmitoylation cycle dynamically regulates partitioning of the GABAsynthesizing enzyme GAD65 between ER-Golgi and post-Golgi membranes. J. Cell Sci. 121, 437-449. doi:10.1242/jcs.011916

Keller, C. A., Yuan, X., Panzanelli, P., Martin, M. L., Alldred, M., Sassoè-Pognetto, M., et al. (2004). The gamma2 subunit of GABA(A) receptors is a substrate for palmitoylation by GODZ. J. Neurosci. 24, 5881-5891. doi:10.1523/ JNEUROSCI.1037-04.2004

Kenworthy, A. K. (2006). Fluorescence-based methods to image palmitoylated proteins. Methods 40, 198-205. doi:10.1016/j.ymeth.2006.06.021

Kischkel, F. C., Hellbardt, S., Behrmann, I., Germer, M., Pawlita, M., Krammer, P. H., et al. (1995). Cytotoxicity-dependent APO-1 (Fas/CD95)-associated proteins form a death-inducing signaling complex (DISC) with the receptor. EMBO J. 14, 5579-5588. doi:10.1002/j.1460-2075.1995.tb00245.x

Kleuss, C., and Krause, E. (2003). Galpha(s) is palmitoylated at the N-terminal glycine. $Е M B O ~ J .22,826-832$. doi:10.1093/emboj/cdg095

Ko, P. J., and Dixon, S. J. (2018). Protein palmitoylation and cancer. EMBO Rep. 19. doi:10.15252/embr.201846666

Koegl, M., Zlatkine, P., Ley, S. C., Courtneidge, S. A., and Magee, A. I. (1994). Palmitoylation of multiple Src-family kinases at a homologous N-terminal motif. Biochem. J. 303 ( Pt 3) (Pt 3), 749-753. doi:10.1042/bj3030749

Kolb, H. C., Finn, M. G., and Sharpless, K. B. (2001). Click chemistry: diverse chemical function from a few good reactions. Angew. Chem. Int. Ed. Engl. 40, 2004-2021. doi:10.1002/1521-3773(20010601)40:11<2004::aid-anie2004>3.0. co;2-5

Kolb, H. C., and Sharpless, K. B. (2003). The growing impact of click chemistry on drug discovery. Drug Discov. Today 8, 1128-1137. doi:10.1016/s1359-6446(03) 02933-7

Kong, C., Lange, J. J., Samovski, D., Su, X., Liu, J., Sundaresan, S., et al. (2013). Ubiquitination and degradation of the hominoid-specific oncoprotein TBC1D3 is regulated by protein palmitoylation. Biochem. Biophys. Res. Commun. 434, 388-393. doi:10.1016/j.bbrc.2013.04.001

Kong, C., Samovski, D., Srikanth, P., Wainszelbaum, M. J., Charron, A. J., Liu, J., et al. (2012). Ubiquitination and degradation of the hominoid-specific oncoprotein TBC1D3 is mediated by CUL7 E3 ligase. PLoS One 7, e46485. doi:10.1371/journal.pone.0046485

Kong, E., Peng, S., Chandra, G., Sarkar, C., Zhang, Z., Bagh, M. B., et al. (2013). Dynamic palmitoylation links cytosol-membrane shuttling of acyl-protein thioesterase-1 and acyl-protein thioesterase-2 with that of proto-oncogene H-ras product and growth-associated protein-43. J. Biol. Chem. 288, 9112-9125. doi:10.1074/jbc.M112.421073

Kordyukova, L. V., Serebryakova, M. V., Baratova, L. A., and Veit, M. (2008). S acylation of the hemagglutinin of influenza viruses: mass spectrometry reveals site-specific attachment of stearic acid to a transmembrane cysteine. J. Virol. 82, 9288-9292. doi:10.1128/JVI.00704-08

Korycka, J., Łach, A., Heger, E., Bogusławska, D. M., Wolny, M., Toporkiewicz, M., et al. (2012). Human DHHC proteins: a spotlight on the hidden player of palmitoylation. Eur. J. Cell Biol. 91, 107-117. doi:10.1016/j.ejcb.2011.09.013

Koster, K. P., and Yoshii, A. (2019). Depalmitoylation by palmitoyl-protein thioesterase 1 in neuronal Health and degeneration. Front. Synaptic Neurosci. 11, 25. doi:10.3389/fnsyn.2019.00025

Kumar, M., Wightman, R., Atanassov, I., Gupta, A., Hurst, C. H., Hemsley, P. A., et al. (2016). S-Acylation of the cellulose synthase complex is essential for its plasma membrane localization. Science 353, 166-169. doi:10.1126/science. aaf4009

Lakkaraju, A. K., Abrami, L., Lemmin, T., Blaskovic, S., Kunz, B., Kihara, A., et al. (2012). Palmitoylated calnexin is a key component of the ribosome-translocon complex. EMBO J. 31, 1823-1835. doi:10.1038/emboj.2012.15

Larsen, J. B., Jensen, M. B., Bhatia, V. K., Pedersen, S. L., Bjørnholm, T., Iversen, L., et al. (2015). Membrane curvature enables N-Ras lipid anchor sorting to liquid-ordered membrane phases. Nat. Chem. Biol. 11, 192-194. doi:10. 1038/nchembio. 1733

Laude, A. J., and Prior, I. A. (2008). Palmitoylation and localisation of RAS isoforms are modulated by the hypervariable linker domain. J. Cell Sci. 121, 421-427. doi:10.1242/jcs.020107

Levental, I., Grzybek, M., and Simons, K. (2010). Greasing their way: lipid modifications determine protein association with membrane rafts. Biochemistry 49, 6305-6316. doi:10.1021/bi100882y

Levental, I., Levental, K. R., and Heberle, F. A. (2020). Lipid rafts: controversies resolved, mysteries remain. Trends Cell Biol. 30, 341-353. doi:10.1016/j.tcb. 2020.01.009

Li, Y., Martin, B. R., Cravatt, B. F., and Hofmann, S. L. (2012). DHHC5 protein palmitoylates flotillin-2 and is rapidly degraded on induction of neuronal differentiation in cultured cells. J. Biol. Chem. 287, 523-530. doi:10.1074/jbc. M111.306183

Li, Y., Wang, S., Chen, Y., Li, M., Dong, X., Hang, H. C., et al. (2020). Site-specific chemical fatty-acylation for gain-of-function analysis of protein S-palmitoylation in live cells. Chem. Commun. (Camb). 56 (89), 13880-13883. doi:10.1039/d0cc06073a

Liang, X., Nazarian, A., Erdjument-Bromage, H., Bornmann, W., Tempst, P., and Resh, M. D. (2001). Heterogeneous fatty acylation of Src family kinases with polyunsaturated fatty acids regulates raft localization and signal transduction. J. Biol. Chem. 276, 30987-30994. doi:10.1074/jbc.M104018200

Lievens, P. M., Kuznetsova, T., Kochlamazashvili, G., Cesca, F., Gorinski, N., Galil, D. A., et al. (2016). ZDHHC3 tyrosine phosphorylation regulates neural cell adhesion molecule palmitoylation. Mol. Cel Biol. 36, 2208-2225. doi:10.1128/ MCB.00144-16

Lin, D. T., and Conibear, E. (2015). ABHD17 proteins are novel protein depalmitoylases that regulate N-Ras palmitate turnover and subcellular localization. Elife 4, e11306. doi:10.7554/eLife.11306

Lin, D. T. S., Davis, N. G., and Conibear, E. (2017). Targeting the Ras palmitoylation/depalmitoylation cycle in cancer. Biochem. Soc. Trans. 45, 913-921. doi:10.1042/BST20160303

Lin, J., Weiss, A., and Finco, T. S. (1999). Localization of LAT in glycolipidenriched microdomains is required for T cell activation. J. Biol. Chem. 274, 28861-28864. doi:10.1074/jbc.274.41.28861

Lin, M. J., Fine, M., Lu, J. Y., Hofmann, S. L., Frazier, G., and Hilgemann, D. W. (2013). Massive palmitoylation-dependent endocytosis during reoxygenation of anoxic cardiac muscle. Elife 2, e01295. doi:10.7554/eLife.01295

Linder, M. E., Middleton, P., Hepler, J. R., Taussig, R., Gilman, A. G., and Mumby, S. M. (1993). Lipid modifications of $G$ proteins: alpha subunits are palmitoylated. Proc. Natl. Acad. Sci. USA 90, 3675-3679. doi:10.1073/pnas. 90.8.3675

Liu, R., Wang, D., Shi, Q., Fu, Q., Hizon, S., and Xiang, Y. K. (2012). Palmitoylation regulates intracellular trafficking of $\beta 2$ adrenergic receptor/arrestin/ phosphodiesterase 4D complexes in cardiomyocytes. PLoS One 7, e42658. doi:10.1371/journal.pone.0042658

Lobo, S., Greentree, W. K., Linder, M. E., and Deschenes, R. J. (2002). Identification of a ras palmitoyltransferase in Saccharomyces cerevisiae. J. Biol. Chem. 277, 41268-41273. doi:10.1074/jbc.M206573200

Long, J. Z., and Cravatt, B. F. (2011). The metabolic serine hydrolases and their functions in mammalian physiology and disease. Chem. Rev. 111, 6022-6063. doi:10.1021/cr200075y

Lorent, J. H., Diaz-Rohrer, B., Lin, X., Spring, K., Gorfe, A. A., Levental, K. R., et al. (2017). Structural determinants and functional consequences of protein affinity for membrane rafts. Nat. Commun. 8, 1219. doi:10.1038/s41467-017-01328-3

Lu, J. Y., and Hofmann, S. L. (2006). Thematic review series: lipid posttranslational modifications. Lysosomal metabolism of lipid-modified proteins. J. Lipid Res. 47, 1352-1357. doi:10.1194/jlr.R600010-JLR200

Magee, A. I., Gutierrez, L., McKay, I. A., Marshall, C. J., and Hall, A. (1987). Dynamic fatty acylation of p21N-ras. EMBO J. 6, 3353-3357. doi:10.1002/j. 1460-2075.1987.tb02656.x

Martin, B. R., and Cravatt, B. F. (2009). Large-scale profiling of protein palmitoylation in mammalian cells. Nat. Methods 6, 135-138. doi:10.1038/ nmeth.1293

Martin, B. R., Wang, C., Adibekian, A., Tully, S. E., and Cravatt, B. F. (2011). Global profiling of dynamic protein palmitoylation. Nat. Methods 9, 84-89. doi:10. 1038/nmeth.1769 
Martin, B. R., Wang, C., Adibekian, A., Tully, S. E., and Cravatt, B. F. (2012). Global profiling of dynamic protein palmitoylation. Nat. Methods 9, 84-89. doi:10. 1038/nmeth.1769

Masuishi, Y., Kimura, Y., Arakawa, N., and Hirano, H. (2016). Identification of glycosylphosphatidylinositol-anchored proteins and $\omega$-sites using TiO2-based affinity purification followed by hydrogen fluoride treatment. J. Proteomics 139, 77-83. doi:10.1016/j.jprot.2016.03.008

Matallanas, D., Sanz-Moreno, V., Arozarena, I., Calvo, F., Agudo-Ibáñez, L., Santos, E., et al. (2006). Distinct utilization of effectors and biological outcomes resulting from site-specific Ras activation: ras functions in lipid rafts and Golgi complex are dispensable for proliferation and transformation. Mol. Cell Biol. 26, 100-116. doi:10.1128/MCB.26.1.100-116.2006

Matt, L., Kim, K., Chowdhury, D., and Hell, J. W. (2019). Role of palmitoylation of postsynaptic proteins in promoting synaptic plasticity. Front. Mol. Neurosci. 12, 8. doi:10.3389/fnmol.2019.00008

Melkonian, K. A., Ostermeyer, A. G., Chen, J. Z., Roth, M. G., and Brown, D. A. (1999). Role of lipid modifications in targeting proteins to detergent-resistant membrane rafts. Many raft proteins are acylated, while few are prenylated. J. Biol. Chem. 274, 3910-3917. doi:10.1074/jbc.274.6.3910

Mellman, I., and Nelson, W. J. (2008). Coordinated protein sorting, targeting and distribution in polarized cells. Nat. Rev. Mol. Cell Biol. 9, 833-845. doi:10.1038/ nrm 2525

Mitchell, D. A., Hamel, L. D., Reddy, K. D., Farh, L., Rettew, L. M., Sanchez, P. R., et al. (2014). Mutations in the X-linked intellectual disability gene, zDHHC9, alter autopalmitoylation activity by distinct mechanisms. J. Biol. Chem. 289, 18582-18592. doi:10.1074/jbc.M114.567420

Mitchell, D. A., Mitchell, G., Ling, Y., Budde, C., and Deschenes, R. J. (2010). Mutational analysis of Saccharomyces cerevisiae Erf2 reveals a two-step reaction mechanism for protein palmitoylation by DHHC enzymes. J. Biol. Chem. 285, 38104-38114. doi:10.1074/jbc.M110.169102

Mitchell, D. A., Vasudevan, A., Linder, M. E., and Deschenes, R. J. (2006). Protein palmitoylation by a family of DHHC protein S-acyltransferases. J. Lipid Res. 47, 1118-1127. doi:10.1194/jlr.R600007-JLR200

Moffett, S., Adam, L., Bonin, H., Loisel, T. P., Bouvier, M., and Mouillac, B. (1996). Palmitoylated cysteine 341 modulates phosphorylation of the beta2-adrenergic receptor by the cAMP-dependent protein kinase. J. Biol. Chem. 271, 21490-21497. doi:10.1074/jbc.271.35.21490

Montigny, C., Decottignies, P., Le Maréchal, P., Capy, P., Bublitz, M., Olesen, C., et al. (2014). S-palmitoylation and s-oleoylation of rabbit and pig sarcolipin. J. Biol. Chem. 289, 33850-33861. doi:10.1074/jbc.M114.590307

Mor, A., and Philips, M. R. (2006). Compartmentalized ras/MAPK signaling. Annu. Rev. Immunol. 24, 771-800. doi:10.1146/annurev.immunol.24.021605. 090723

Morozova, D., and Weiss, M. (2010). On the role of acylation of transmembrane proteins. Biophys. J. 98, 800-804. doi:10.1016/j.bpj.2009.11.014

Mukai, J., Liu, H., Burt, R. A., Swor, D. E., Lai, W. S., Karayiorgou, M., et al. (2004). Evidence that the gene encoding ZDHHC8 contributes to the risk of schizophrenia. Nat. Genet. 36, 725-731. doi:10.1038/ng1375

Muszbek, L., Haramura, G., Cluette-Brown, J. E., Van Cott, E. M., and Laposata, M. (1999). The pool of fatty acids covalently bound to platelet proteins by thioester linkages can be altered by exogenously supplied fatty acids. Lipids 34 Suppl (Suppl. 1), S331-S337. doi:10.1007/BF02562334

Nadolski, M. J., and Linder, M. E. (2009). Molecular recognition of the palmitoylation substrate Vac8 by its palmitoyltransferase Pfa3. J. Biol. Chem. 284, 17720-17730. doi:10.1074/jbc.M109.005447

Naeve, C. W., and Williams, D. (1990). Fatty acids on the A/Japan/305/57 influenza virus hemagglutinin have a role in membrane fusion. EMBO J. 9, 3857-3866. doi:10.1002/j.1460-2075.1990.tb07604.x

Nagata, S. (1997). Apoptosis by death factor. Cell 88, 355-365. doi:10.1016/s00928674(00)81874-7

Nievas, Y. R., Vashisht, A. A., Corvi, M. M., Metz, S., Johnson, P. J., Wohlschlegel, J. A., et al. (2018). Protein palmitoylation plays an important role in trichomonas vaginalis adherence. Mol. Cel Proteomics 17, 2229-2241. doi:10. 1074/mcp.RA117.000018

Nüsslein-Volhard, C., and Wieschaus, E. (1980). Mutations affecting segment number and polarity in Drosophila. Nature 287, 795-801. doi:10.1038/ $287795 \mathrm{a} 0$
O’Dowd, B. F., Hnatowich, M., Caron, M. G., Lefkowitz, R. J., and Bouvier, M. (1989). Palmitoylation of the human beta 2-adrenergic receptor. Mutation of Cys341 in the carboxyl tail leads to an uncoupled nonpalmitoylated form of the receptor. J. Biol. Chem. 264, 7564-7569. doi:10.1016/s0021-9258(18) 83271-9

Ohno, Y., Kihara, A., Sano, T., and Igarashi, Y. (2006). Intracellular localization and tissue-specific distribution of human and yeast DHHC cysteine-rich domaincontaining proteins. Biochim. Biophys. Acta 1761, 474-483. doi:10.1016/j. bbalip.2006.03.010

Old, W. M., Meyer-Arendt, K., Aveline-Wolf, L., Pierce, K. G., Mendoza, A., Sevinsky, J. R., et al. (2005). Comparison of label-free methods for quantifying human proteins by shotgun proteomics. Mol. Cell Proteomics 4, 1487-1502. doi:10.1074/mcp.M500084-MCP200

Ong, S. E., Blagoev, B., Kratchmarova, I., Kristensen, D. B., Steen, H., Pandey, A., et al. (2002). Stable isotope labeling by amino acids in cell culture, SILAC, as a simple and accurate approach to expression proteomics. Mol. Cell Proteomics 1, 376-386. doi:10.1074/mcp.m200025-mcp200

Oo, H. Z., Sentani, K., Sakamoto, N., Anami, K., Naito, Y., Uraoka, N., et al. (2014). Overexpression of ZDHHC14 promotes migration and invasion of scirrhous type gastric cancer. Oncol. Rep. 32, 403-410. doi:10.3892/or.2014.3166

Ostrom, R. S., Gregorian, C., Drenan, R. M., Xiang, Y., Regan, J. W., and Insel, P. A. (2001). Receptor number and caveolar co-localization determine receptor coupling efficiency to adenylyl cyclase. J. Biol. Chem. 276, 42063-42069. doi:10.1074/jbc.M105348200

Paige, L. A., Nadler, M. J., Harrison, M. L., Cassady, J. M., and Geahlen, R. L. (1993). Reversible palmitoylation of the protein-tyrosine kinase p56lck. J. Biol. Chem. 268, 8669-8674. doi:10.1016/s0021-9258(18)52927-6

Parolini, I., Sargiacomo, M., Lisanti, M. P., and Peschle, C. (1996). Signal transduction and glycophosphatidylinositol-linked proteins (lyn, lck, CD4, CD45, G proteins, and CD55) selectively localize in Triton-insoluble plasma membrane domains of human leukemic cell lines and normal granulocytes. Blood 87, 3783-3794. doi:10.1182/blood.v87.9.3783.bloodjournal8793783

Parton, R. G., and Richards, A. A. (2003). Lipid rafts and caveolae as portals for endocytosis: new insights and common mechanisms. Traffic 4, 724-738. doi:10. 1034/j.1600-0854.2003.00128.x

Patterson, G. H., Hirschberg, K., Polishchuk, R. S., Gerlich, D., Phair, R. D., and Lippincott-Schwartz, J. (2008). Transport through the Golgi apparatus by rapid partitioning within a two-phase membrane system. Cell 133, 1055-1067. doi:10. 1016/j.cell.2008.04.044

Patterson, S. I., and Skene, J. H. (1995). Inhibition of dynamic protein palmitoylation in intact cells with tunicamycin. Meth Enzymol. 250, 284-300. doi:10.1016/0076-6879(95)50079-0

Pei, L., Peng, Y., Yang, Y., Ling, X. B., Van Eyndhoven, W. G., Nguyen, K. C., et al. (2002). PRC17, a novel oncogene encoding a Rab GTPase-activating protein, is amplified in prostate cancer. Cancer Res. 62, 5420-5424.

Pei, Z., Xiao, Y., Meng, J., Hudmon, A., and Cummins, T. R. (2016). Cardiac sodium channel palmitoylation regulates channel availability and myocyte excitability with implications for arrhythmia generation. Nat. Commun. 7, 12035. doi:10.1038/ncomms 12035

Peng, C., Zhang, Z., Wu, J., Lv, Z., Tang, J., Xie, H., et al. (2014). A critical role for ZDHHC2 in metastasis and recurrence in human hepatocellular carcinoma. Biomed. Res. Int. 2014, 832712. doi:10.1155/2014/832712

Percher, A., Ramakrishnan, S., Thinon, E., Yuan, X., Yount, J. S., and Hang, H. C. (2016). Mass-tag labeling reveals site-specific and endogenous levels of protein S-fatty acylation. Proc. Natl. Acad. Sci. USA 113, 4302-4307. doi:10.1073/pnas. 1602244113

Percherancier, Y., Planchenault, T., Valenzuela-Fernandez, A., Virelizier, J. L., Arenzana-Seisdedos, F., and Bachelerie, F. (2001). Palmitoylation-dependent control of degradation, life span, and membrane expression of the CCR5 receptor. J. Biol. Chem. 276, 31936-31944. doi:10.1074/jbc.M104013200

Perrody, E., Abrami, L., Feldman, M., Kunz, B., Urbé, S., and van der Goot, F. G. (2016). Ubiquitin-dependent folding of the Wnt signaling coreceptor LRP6. Elife 5. doi:10.7554/eLife.19083

Petit, C. M., Chouljenko, V. N., Iyer, A., Colgrove, R., Farzan, M., Knipe, D. M., et al. (2007). Palmitoylation of the cysteine-rich endodomain of the SARScoronavirus spike glycoprotein is important for spike-mediated cell fusion. Virology 360, 264-274. doi:10.1016/j.virol.2006.10.034 
Philippe, J. M., and Jenkins, P. M. (2019). Spatial organization of palmitoyl acyl transferases governs substrate localization and function. Mol. Membr. Biol. 35, 60-75. doi:10.1080/09687688.2019.1710274

Plain, F., Howie, J., Kennedy, J., Brown, E., Shattock, M. J., Fraser, N. J., et al. (2020). Control of protein palmitoylation by regulating substrate recruitment to a zDHHC-protein acyltransferase. Commun. Biol. 3, 411. doi:10.1038/s42003020-01145-3

Porter, J. A., Young, K. E., and Beachy, P. A. (1996). Cholesterol modification of hedgehog signaling proteins in animal development. Science 274, 255-259. doi:10.1126/science.274.5285.255

Rana, M. S., Kumar, P., Lee, C. J., Verardi, R., Rajashankar, K. R., and Banerjee, A. (2018). Fatty acyl recognition and transfer by an integral membrane S-acyltransferase. Science 359. doi:10.1126/science.aao6326

Raymond, F. L., Tarpey, P. S., Edkins, S., Tofts, C., O’Meara, S., Teague, J., et al. (2007). Mutations in ZDHHC9, which encodes a palmitoyltransferase of NRAS and HRAS, cause X-linked mental retardation associated with a Marfanoid habitus. Am. J. Hum. Genet. 80, 982-987. doi:10.1086/513609

Ren, W., Sun, Y., and Du, K. (2015). Glut4 palmitoylation at Cys223 plays a critical role in Glut4 membrane trafficking. Biochem. Biophys. Res. Commun. 460, 709-714. doi:10.1016/j.bbrc.2015.03.094

Resh, M. D. (2013). Covalent lipid modifications of proteins. Curr. Biol. 23, R431-R435. doi:10.1016/j.cub.2013.04.024

Rocks, O., Gerauer, M., Vartak, N., Koch, S., Huang, Z. P., Pechlivanis, M., et al. (2010). The palmitoylation machinery is a spatially organizing system for peripheral membrane proteins. Cell 141, 458-471. doi:10.1016/j.cell.2010. 04.007

Rocks, O., Peyker, A., Kahms, M., Verveer, P. J., Koerner, C., Lumbierres, M., et al. (2005). An acylation cycle regulates localization and activity of palmitoylated Ras isoforms. Science 307, 1746-1752. doi:10.1126/science.1105654

Rodenburg, R. N. P., Snijder, J., van de Waterbeemd, M., Schouten, A., Granneman, J., Heck, A. J. R., et al. (2017). Stochastic palmitoylation of accessible cysteines in membrane proteins revealed by native mass spectrometry. Nat. Commun. 8 , 1280. doi:10.1038/s41467-017-01461-z

Rodgers, W., Crise, B., and Rose, J. K. (1994). Signals determining protein tyrosine kinase and glycosyl-phosphatidylinositol-anchored protein targeting to a glycolipid-enriched membrane fraction. Mol. Cell Biol. 14, 5384-5391. doi:10.1128/mcb.14.8.5384

Rossin, A., Durivault, J., Chakhtoura-Feghali, T., Lounnas, N., Gagnoux-Palacios, L., and Hueber, A. O. (2015). Fas palmitoylation by the palmitoyl acyltransferase DHHC7 regulates Fas stability. Cell Death Differ. 22, 643-653. doi:10.1038/cdd.2014.153

Roth, A. F., Feng, Y., Chen, L., and Davis, N. G. (2002). The yeast DHHC cysteinerich domain protein Akrlp is a palmitoyl transferase. J. Cell Biol. 159, 23-28. doi:10.1083/jcb.200206120

Roth, A. F., Wan, J., Bailey, A. O., Sun, B., Kuchar, J. A., Green, W. N., et al. (2006). Global analysis of protein palmitoylation in yeast. Cell 125, 1003-1013. doi:10. 1016/j.cell.2006.03.042

Rybin, V. O., Xu, X., Lisanti, M. P., and Steinberg, S. F. (2000). Differential targeting of beta -adrenergic receptor subtypes and adenylyl cyclase to cardiomyocyte caveolae. A mechanism to functionally regulate the cAMP signaling pathway. J. Biol. Chem. 275, 41447-41457. doi:10.1074/jbc.M006951200

Salaün, C., Gould, G. W., and Chamberlain, L. H. (2005). The SNARE proteins SNAP-25 and SNAP-23 display different affinities for lipid rafts in PC12 cells. Regulation by distinct cysteine-rich domains. J. Biol. Chem. 280, 1236-1240. doi:10.1074/jbc.M410674200

Salaun, C., Greaves, J., and Chamberlain, L. H. (2010). The intracellular dynamic of protein palmitoylation. J. Cell Biol. 191, 1229-1238. doi:10.1083/jcb.201008160

Schlesinger, M. J., Magee, A. I., and Schmidt, M. F. (1980). Fatty acid acylation of proteins in cultured cells. J. Biol. Chem. 255, 10021-10024. doi:10.1016/s00219258(19)70417-7

Senyilmaz, D., Virtue, S., Xu, X., Tan, C. Y., Griffin, J. L., Miller, A. K., et al. (2015). Regulation of mitochondrial morphology and function by stearoylation of TFR1. Nature 525, 124-128. doi:10.1038/nature14601

Shahinian, S., and Silvius, J. R. (1995). Doubly-lipid-modified protein sequence motifs exhibit long-lived anchorage to lipid bilayer membranes. Biochemistry 34, 3813-3822. doi:10.1021/bi00011a039

Sharma, C., Wang, H. X., Li, Q., Knoblich, K., Reisenbichler, E. S., Richardson, A. L., et al. (2017). Protein acyltransferase DHHC3 regulates breast tumor growth, oxidative stress and senescence. Cancer Res. 77, 6880-6890. doi:10.1158/00085472.CAN-17-1536

Sharma, C., Yang, X. H., and Hemler, M. E. (2008). DHHC2 affects palmitoylation, stability, and functions of tetraspanins CD9 and CD151. Mol. Biol. Cell 19, 3415-3425. doi:10.1091/mbc.E07-11-1164

Shayahati, B., Fan, Y., West, S., Tewari, R., Ko, J., Mills, T., et al. (2020). Calciumdependent protein acyltransferase DHHC21 controls activation of $\mathrm{CD} 4^{+} \mathrm{T}$ cells, bioRxiv. doi:10.1101/2020.09.01.277947

Shenoy-Scaria, A. M., Gauen, L. K., Kwong, J., Shaw, A. S., and Lublin, D. M. (1993). Palmitylation of an amino-terminal cysteine motif of protein tyrosine kinases p56lck and p59fyn mediates interaction with glycosylphosphatidylinositol-anchored proteins. Mol. Cell Biol. 13, 6385-6392. doi:10.1128/mcb.13.10.6385

Shi, Y., Veit, B., and Baekkeskov, S. (1994). Amino acid residues 24-31 but not palmitoylation of cysteines 30 and 45 are required for membrane anchoring of glutamic acid decarboxylase, GAD65. J. Cell Biol. 124, 927-934. doi:10.1083/jcb. 124.6.927

Shimell, J. J., Shah, B. S., Cain, S. M., Thouta, S., Kuhlmann, N., Tatarnikov, I., et al. (2019). The X-linked intellectual disability gene Zdhhc9 is essential for dendrite outgrowth and inhibitory synapse formation. Cell Rep. 29, 2422-e8. doi:10. 1016/j.celrep.2019.10.065

Shulla, A., and Gallagher, T. (2009). Role of spike protein endodomains in regulating coronavirus entry. J. Biol. Chem. 284, 32725-32734. doi:10.1074/ jbc.M109.043547

Siegel, G., Obernosterer, G., Fiore, R., Oehmen, M., Bicker, S., Christensen, M., et al. (2009). A functional screen implicates microRNA-138-dependent regulation of the depalmitoylation enzyme APT1 in dendritic spine morphogenesis. Nat. Cel Biol. 11, 705-716. doi:10.1038/ncb1876

Simons, K., and Toomre, D. (2000). Lipid rafts and signal transduction. Nat. Rev. Mol. Cel Biol 1, 31-39. doi:10.1038/35036052

Singaraja, R. R., Huang, K., Sanders, S. S., Milnerwood, A. J., Hines, R., Lerch, J. P., et al. (2011). Altered palmitoylation and neuropathological deficits in mice lacking HIP14. Hum. Mol. Genet. 20, 3899-3909. doi:10.1093/hmg/ ddr308

Smotrys, J. E., Schoenfish, M. J., Stutz, M. A., and Linder, M. E. (2005). The vacuolar DHHC-CRD protein Pfa3p is a protein acyltransferase for Vac8p J. Cel Biol. 170, 1091-1099. doi:10.1083/jcb.200507048

Sobocinska, J., Roszczenko-Jasinska, P., Zareba-Koziol, M., Hromada-Judycka, A., Matveichuk, O. V., Traczyk, G., et al. (2018). Lipopolysaccharide upregulates palmitoylated enzymes of the phosphatidylinositol cycle: an insight from proteomic studies. Mol. Cell Proteomics 17, 233-254.

Steinberg, S. F., and Brunton, L. L. (2001). Compartmentation of G proteincoupled signaling pathways in cardiac myocytes. Annu. Rev. Pharmacol. Toxicol. 41, 751-773. doi:10.1146/annurev.pharmtox.41.1.751

Stokoe, D., Macdonald, S. G., Cadwallader, K., Symons, M., and Hancock, J. F. (1994). Activation of Raf as a result of recruitment to the plasma membrane. Science 264, 1463-1467. doi:10.1126/science.7811320

Sutton, L. M., Sanders, S. S., Butland, S. L., Singaraja, R. R., Franciosi, S., Southwell, A. L., et al. (2013). Hipl41-deficient mice develop neuropathological and behavioural features of Huntington disease. Hum. Mol. Genet. 22, 452-465. doi: $10.1093 / \mathrm{hmg} / \mathrm{dds} 441$

Swarthout, J. T., Lobo, S., Farh, L., Croke, M. R., Greentree, W. K., Deschenes, R. J., et al. (2005). DHHC9 and GCP16 constitute a human protein fatty acyltransferase with specificity for $\mathrm{H}-$ and N-Ras. J. Biol. Chem. 280, 31141-31148. doi:10.1074/jbc.M504113200

Tabaczar, S., Czogalla, A., Podkalicka, J., Biernatowska, A., and Sikorski, A. F. (2017). Protein palmitoylation: palmitoyltransferases and their specificity. Exp. Biol. Med. 242, 1150-1157. doi:10.1177/1535370217707732

Takeda, M., Leser, G. P., Russell, C. J., and Lamb, R. A. (2003). Influenza virus hemagglutinin concentrates in lipid raft microdomains for efficient viral fusion. Proc. Natl. Acad. Sci. USA 100, 14610-14617. doi:10.1073/pnas. 2235620100

Thinon, E., Percher, A., and Hang, H. C. (2016). Bioorthogonal chemical reporters for monitoring unsaturated fatty-acylated proteins. Chembiochem 17, 1800-1803. doi:10.1002/cbic.201600213

Thinon, E., Serwa, R. A., Broncel, M., Brannigan, J. A., Brassat, U., Wright, M. H., et al. (2014). Global profiling of co- and post-translationally N-myristoylated proteomes in human cells. Nat. Commun. 5, 4919. doi:10.1038/ncomms5919 
Thomas, G. M., Hayashi, T., Chiu, S. L., Chen, C. M., and Huganir, R. L. (2012). Palmitoylation by DHHC5/8 targets GRIP1 to dendritic endosomes to regulate AMPA-R trafficking. Neuron 73, 482-496. doi:10.1016/j.neuron.2011.11.021

Thorp, E. B., Boscarino, J. A., Logan, H. L., Goletz, J. T., and Gallagher, T. M. (2006). Palmitoylations on murine coronavirus spike proteins are essential for virion assembly and infectivity. J. Virol. 80, 1280-1289. doi:10.1128/JVI.80.3. 1280-1289.2006

Tian, H., Lu, J. Y., Shao, C., Huffman, K. E., Carstens, R. M., Larsen, J. E., et al. (2015). Systematic siRNA screen unmasks NSCLC growth dependence by palmitoyltransferase DHHC5. Mol. Cancer Res. 13, 784-794. doi:10.1158/ 1541-7786.MCR-14-0608

Tomatis, V. M., Trenchi, A., Gomez, G. A., and Daniotti, J. L. (2010). Acyl-protein thioesterase 2 catalyzes the deacylation of peripheral membrane-associated GAP-43. PLoS One 5, e15045. doi:10.1371/journal.pone.0015045

Topinka, J. R., and Bredt, D. S. (1998). N-terminal palmitoylation of PSD-95 regulates association with cell membranes and interaction with $\mathrm{K}+$ channel Kv1.4. Neuron 20, 125-134. doi:10.1016/s0896-6273(00)80440-7

Tortosa, E., Adolfs, Y., Fukata, M., Pasterkamp, R. J., Kapitein, L. C., and Hoogenraad, C. C. (2017). Dynamic palmitoylation targets MAP6 to the axon to promote microtubule stabilization during neuronal polarization. Neuron 94, e809-e807. doi:10.1016/j.neuron.2017.04.042

Tsutsumi, R., Fukata, Y., Noritake, J., Iwanaga, T., Perez, F., and Fukata, M. (2009). Identification of $\mathrm{G}$ protein alpha subunit-palmitoylating enzyme. Mol. Cell Biol. 29, 435-447. doi:10.1128/MCB.01144-08

Tulloch, L. B., Howie, J., Wypijewski, K. J., Wilson, C. R., Bernard, W. G., Shattock, M. J., et al. (2011). The inhibitory effect of phospholemman on the sodium pump requires its palmitoylation. J. Biol. Chem. 286, 36020-36031. doi:10.1074/ jbc.M111.282145

Valdez-Taubas, J., and Pelham, H. (2005). Swf1-dependent palmitoylation of the SNARE Tlg1 prevents its ubiquitination and degradation. EMBO J. 24, 2524-2532. doi:10.1038/sj.emboj.7600724

van der Weyden, L., Arends, M. J., Campbell, A. D., Bald, T., Wardle-Jones, H., Griggs, N., et al. (2017). Genome-wide in vivo screen identifies novel host regulators of metastatic colonization. Nature 541, 233-236. doi:10.1038/ nature20792

Vartak, N., Papke, B., Grecco, H. E., Rossmannek, L., Waldmann, H., Hedberg, C., et al. (2014). The autodepalmitoylating activity of APT maintains the spatial organization of palmitoylated membrane proteins. Biophys. J. 106, 93-105. doi:10.1016/j.bpj.2013.11.024

Veit, M., Ponimaskin, E., and Schmidt, M. F. (2008). Analysis of S-acylation of proteins. Methods Mol. Biol. 446, 163-182. doi:10.1007/978-1-60327-084-7_12

Verkruyse, L. A., and Hofmann, S. L. (1996). Lysosomal targeting of palmitoylprotein thioesterase. J. Biol. Chem. 271, 15831-15836. doi:10.1074/jbc.271.26. 15831

Vesa, J., Hellsten, E., Verkruyse, L. A., Camp, L. A., Rapola, J., Santavuori, P., et al. (1995). Mutations in the palmitoyl protein thioesterase gene causing infantile neuronal ceroid lipofuscinosis. Nature 376, 584-587. doi:10.1038/376584a0

Wan, J., Roth, A. F., Bailey, A. O., and Davis, N. G. (2007). Palmitoylated proteins: purification and identification. Nat. Protoc. 2, 1573-1584. doi:10.1038/nprot. 2007.225

Wan, J., Savas, J. N., Roth, A. F., Sanders, S. S., Singaraja, R. R., Hayden, M. R., et al. (2013). Tracking brain palmitoylation change: predominance of glial change in a mouse model of Huntington's disease. Chem. Biol. 20, 1421-1434. doi:10. 1016/j.chembiol.2013.09.018

Wang, M., and Casey, P. J. (2016). Protein prenylation: unique fats make their mark on biology. Nat. Rev. Mol. Cell Biol. 17, 110-122. doi:10.1038/nrm.2015.11

Wang, Q., Chan, T. R., Hilgraf, R., Fokin, V. V., Sharpless, K. B., and Finn, M. G. (2003). Bioconjugation by copper(I)-catalyzed azide-alkyne $[3+2]$ cycloaddition. J. Am. Chem. Soc. 125, 3192-3193. doi:10.1021/ja021381e

Wang, Y., and Yang, W. (2021). Proteome-scale Analysis of protein S-acylation comes of age. J. Proteome Res. 20, 14-26. doi:10.1021/acs.jproteome.0c00409

Webb, Y., Hermida-Matsumoto, L., and Resh, M. D. (2000). Inhibition of protein palmitoylation, raft localization, and T cell signaling by 2-bromopalmitate and polyunsaturated fatty acids. J. Biol. Chem. 275, 261-270. doi:10.1074/jbc.275. 1.261

Wedegaertner, P. B., Chu, D. H., Wilson, P. T., Levis, M. J., and Bourne, H. R. (1993). Palmitoylation is required for signaling functions and membrane attachment of Gq alpha and Gs alpha. J. Biol. Chem. 268, 25001-25008. doi:10.1016/s0021-9258(19)74563-3

Wilcox, C., Hu, J. S., and Olson, E. N. (1987). Acylation of proteins with myristic acid occurs cotranslationally. Science 238, 1275-1278. doi:10.1126/science. 3685978

Wolfson-Stofko, B., Hadi, T., and Blanchard, J. S. (2013). Kinetic and mechanistic characterization of the glyceraldehyde 3-phosphate dehydrogenase from Mycobacterium tuberculosis. Arch. Biochem. Biophys. 540, 53-61. doi:10. 1016/j.abb.2013.10.007

Won, S. J., Davda, D., Labby, K. J., Hwang, S. Y., Pricer, R., Majmudar, J. D., et al. (2016). Molecular mechanism for isoform-selective inhibition of acyl protein thioesterases 1 and 2 (APT1 and APT2). ACS Chem. Biol. 11, 3374-3382. doi:10.1021/acschembio.6b00720

Woodley, K. T., and Collins, M. O. (2019). S-acylated Golga7b stabilises DHHC5 at the plasma membrane to regulate cell adhesion. EMBO Rep. 20, e47472. doi:10. 15252/embr.201847472

Wright, M. H., Clough, B., Rackham, M. D., Rangachari, K., Brannigan, J. A., Grainger, M., et al. (2014). Validation of N-myristoyltransferase as an antimalarial drug target using an integrated chemical biology approach. Nat. Chem. 6, 112-121. doi:10.1038/nchem.1830

Wu, J., Jiao, Y., Dal Molin, M., Maitra, A., de Wilde, R. F., Wood, L. D., et al. (2011). Whole-exome sequencing of neoplastic cysts of the pancreas reveals recurrent mutations in components of ubiquitin-dependent pathways. Proc. Natl. Acad. Sci. USA 108, 21188-21193. doi:10.1073/pnas.1118046108

Yamamoto, Y., Chochi, Y., Matsuyama, H., Eguchi, S., Kawauchi, S., Furuya, T., et al. (2007). Gain of 5p15.33 is associated with progression of bladder cancer. Oncology 72, 132-138. doi:10.1159/000111132

Yamazaki, M., Fukaya, M., Abe, M., Ikeno, K., Kakizaki, T., Watanabe, M., et al. (2001). Differential palmitoylation of two mouse glutamate receptor interacting protein 1 forms with different N-terminal sequences. Neurosci. Lett. 304, 81-84. doi:10.1016/s0304-3940(01)01766-9

Yan, S. M., Tang, J. J., Huang, C. Y., Xi, S. Y., Huang, M. Y., Liang, J. Z., et al. (2013). Reduced expression of ZDHHC2 is associated with lymph node metastasis and poor prognosis in gastric adenocarcinoma. PLoS One 8, e56366. doi:10.1371/ journal.pone.0056366

Yanai, A., Huang, K., Kang, R., Singaraja, R. R., Arstikaitis, P., Gan, L., et al. (2006). Palmitoylation of huntingtin by HIP14 is essential for its trafficking and function. Nat. Neurosci. 9, 824-831. doi:10.1038/nn1702

Yang, Q., Zheng, F., Hu, Y., Yang, Y., Li, Y., Chen, G., et al. (2018). ZDHHC8 critically regulates seizure susceptibility in epilepsy. Cell Death Dis. 9, 795. doi:10.1038/s41419-018-0842-0

Yang, W., Di Vizio, D., Kirchner, M., Steen, H., and Freeman, M. R. (2010). Proteome scale characterization of human S-acylated proteins in lipid raftenriched and non-raft membranes. Mol. Cell Proteomics 9, 54-70. doi:10.1074/ mcp.M800448-MCP200

Yeh, D. C., Duncan, J. A., Yamashita, S., and Michel, T. (1999). Depalmitoylation of endothelial nitric-oxide synthase by acyl-protein thioesterase 1 is potentiated by $\mathrm{Ca}(2+)$-calmodulin. J. Biol. Chem. 274, 33148-33154. doi:10.1074/jbc.274.46. 33148

Yeste-Velasco, M., Linder, M. E., and Lu, Y. J. (2015). Protein S-palmitoylation and cancer. Biochim. Biophys. Acta 1856, 107-120. doi:10.1016/j.bbcan.2015.06.004

Yokoi, N., Fukata, Y., Sekiya, A., Murakami, T., Kobayashi, K., and Fukata, M. (2016). Identification of PSD-95 depalmitoylating enzymes. J. Neurosci. 36, 6431-6444. doi:10.1523/JNEUROSCI.0419-16.2016

Yount, J. S., Moltedo, B., Yang, Y. Y., Charron, G., Moran, T. M., López, C. B., et al. (2010). Palmitoylome profiling reveals S-palmitoylation-dependent antiviral activity of IFITM3. Nat. Chem. Biol. 6, 610-614. doi:10.1038/ nchembio. 405

Yurchak, L. K., and Sefton, B. M. (1995). Palmitoylation of either Cys-3 or Cys-5 is required for the biological activity of the Lck tyrosine protein kinase. Mol. Cell Biol. 15, 6914-6922. doi:10.1128/mcb.15.12.6914

Zeidman, R., Jackson, C. S., and Magee, A. I. (2009). Protein acyl thioesterases (Review). Mol. Membr. Biol. 26, 32-41. doi:10.1080/09687680802629329

Zelus, B. D., Schickli, J. H., Blau, D. M., Weiss, S. R., and Holmes, K. V. (2003). Conformational changes in the spike glycoprotein of murine coronavirus are induced at 37 degrees $\mathrm{C}$ either by soluble murine CEACAM1 receptors or by $\mathrm{pH}$ 8. J. Virol. 77, 830-840. doi:10.1128/jvi.77.2.830-840.2003 
Zhang, M. M., Tsou, L. K., Charron, G., Raghavan, A. S., and Hang, H. C. (2010). Tandem fluorescence imaging of dynamic S-acylation and protein turnover. Proc. Natl. Acad. Sci. USA 107, 8627-8632. doi:10.1073/pnas.0912306107

Zhang, W., Trible, R. P., and Samelson, L. E. (1998). LAT palmitoylation: its essential role in membrane microdomain targeting and tyrosine phosphorylation during T cell activation. Immunity 9, 239-246. doi:10.1016/ s1074-7613(00)80606-8

Zhang, X., Zhang, L., Ji, G., Lei, Q., Fang, C., and Lu, H. (2018a). Site-specific quantification of protein palmitoylation by cysteine-stable isotope metabolic labeling. Anal. Chem. 90, 10543-10550. doi:10.1021/acs.analchem.8b02635

Zhang, X., Zhang, Y., Fang, C., Zhang, L., Yang, P., Wang, C., et al. (2018b). Ultradeep palmitoylomics enabled by dithiodipyridine-functionalized magnetic nanoparticles. Anal. Chem. 90, 6161-6168. doi:10.1021/acs.analchem.8b00534

Zhu, Y. C., Li, D., Wang, L., Lu, B., Zheng, J., Zhao, S. L., et al. (2013). Palmitoylation-dependent CDKL5-PSD-95 interaction regulates synaptic targeting of CDKL5 and dendritic spine development. Proc. Natl. Acad. Sci. USA 110, 9118-9123. doi:10.1073/pnas.1300003110

Zou, C., Ellis, B. M., Smith, R. M., Chen, B. B., Zhao, Y., and Mallampalli, R. K. (2011). Acyl-CoA:lysophosphatidylcholine acyltransferase I (Lpcat1) catalyzes histone protein O-palmitoylation to regulate mRNA synthesis. J. Biol. Chem. 286, 28019-28025. doi:10.1074/jbc.M111.253385

Zurcher, T., Luo, G., and Palese, P. (1994). Mutations at palmitylation sites of the influenza virus hemagglutinin affect virus formation. J. Virol. 68, 5748-5754. doi:10.1128/JVI.68.9.5748-5754.1994

Zurzolo, C., and Simons, K. (2016). Glycosylphosphatidylinositol-anchored proteins: membrane organization and transport. Biochim. Biophys. Acta 1858, 632-639. doi:10.1016/j.bbamem.2015.12.018

Conflict of Interest: The authors declare that the research was conducted in the absence of any commercial or financial relationships that could be considered as potential conflict of interest.

Copyright $(2) 2021$ Chen, Fan and Boehning. This is an open-access article distributed under the terms of the Creative Commons Attribution License (CC BY). The use, distribution or reproduction in other forums is permitted, provided the original author(s) and the copyright owner(s) are credited and that the original publication in this journal is cited, in accordance with accepted academic practice. No use, distribution or reproduction is permitted which does not comply with these terms. 